\title{
Four cellulose-active lytic polysaccharide monooxygenases from Cellulomonas species
}

James Li1,2,6, Laleh Solhi 1,6, Ethan D. Goddard-Borger ${ }^{3}$, Yann Mathieu ${ }^{1,6}$, Warren W. Wakarchuk4, Stephen G. Withers ${ }^{1,2,3,6}$ and Harry Brumer ${ }^{1,2,3,5,6^{*}}$ (D)

\begin{abstract}
Background: The discovery of lytic polysaccharide monooxygenases (LPMOs) has fundamentally changed our understanding of microbial lignocellulose degradation. Cellulomonas bacteria have a rich history of study due to their ability to degrade recalcitrant cellulose, yet little is known about the predicted LPMOs that they encode from Auxiliary Activity Family 10 (AA10).

Results: Here, we present the comprehensive biochemical characterization of three AA10 LPMOs from Cellulomonas flavigena (CflaLPMO10A, CflaLPMO10B, and CflaLPMO10C) and one LPMO from Cellulomonas fimi (CFiLPMO10). We demonstrate that these four enzymes oxidize insoluble cellulose with $\mathrm{C} 1$ regioselectivity and show a preference for substrates with high surface area. In addition, CflaLPMO10B, CflaLPMO10C, and CfiLPMO10 exhibit limited capacity to perform mixed C1/C4 regioselective oxidative cleavage. Thermostability analysis indicates that these LPMOs can refold spontaneously following denaturation dependent on the presence of copper coordination. Scanning and transmission electron microscopy revealed substrate-specific surface and structural morphological changes following LPMO action on Avicel and phosphoric acid-swollen cellulose (PASC). Further, we demonstrate that the LPMOs encoded by Cellulomonas flavigena exhibit synergy in cellulose degradation, which is due in part to decreased autoinactivation.

Conclusions: Together, these results advance understanding of the cellulose utilization machinery of historically important Cellulomonas species beyond hydrolytic enzymes to include lytic cleavage. This work also contributes to the broader mapping of enzyme activity in Auxiliary Activity Family 10 and provides new biocatalysts for potential applications in biomass modification.
\end{abstract}

Keywords: LPMO, AA10, Cellulose, Biomass, Bioethanol, Bioproducts

\section{Background}

The development of second-generation bioethanol and other chemicals from renewable plant biomass is primarily limited by the intrinsic difficulty in depolymerizing the complex matrix of cellulose, hemicellulose, and lignin comprising lignocellulose. Specifically, the highly stabilizing hydrogen bonding network and stacking interactions between cellulose chains $[1,2]$, together with the

*Correspondence: brumer@msl.ubc.ca

${ }^{1}$ Michael Smith Laboratories, University of British Columbia, 2185 East Mall, Vancouver, BC V6T 1Z4, Canada

Full list of author information is available at the end of the article composite nature of lignocellulose, limit the ability of hydrolytic enzymes to access the scissile $\beta(1,4)$-glucan linkages. As such, many novel methodologies for biomass pretreatment have been developed over the past decades $[3,4]$ to overcome the problem of substrate recalcitrance. In harness, enzyme discovery and enzyme engineering approaches have continued to deliver new and improved biocatalysts for lignocellulose degradation. Indeed, bacteria and fungi have evolved elegant strategies for complete biomass breakdown, which has prompted detailed exploration of the secretomes of certain highly cellulolytic organisms [5-8]. Traditionally, much of the research on microbial lignocellulose breakdown has focused on the 
glycoside hydrolases, and specifically the secreted endoglucanases (EG) and exo-glucanases (cellobiohydrolases, $\mathrm{CBH}$ ) responsible for carbohydrate saccharification [915]. As a result, many cellulolytic enzyme cocktails [16, 17] and engineered organisms [18-22] have been developed, which have significantly advanced industrial biomass conversion.

Nonetheless, it has been long recognized that hydrolytic cellulases are not particularly efficient in catalyzing the conversion of paracrystalline cellulose into fermentable glucose. Seminal studies over the last decade have revealed the existence of copper-dependent lytic polysaccharide monooxygenases (LPMOs), which oxidatively cleave the cellulose chain thereby potentiating the activity of hydrolytic enzymes (chitin-, starch-, and hemicellulose-active LPMOs are also known) [23-29]. Several sequence-similar families of LPMOs are now known, which are classified in the CAZy database as Auxiliary Activity (AA) families AA9, AA10, AA11, AA13, AA14, AA15, and AA16 [30-34]. LPMOs are currently known to be encoded in genomes across all kingdoms of life, as well as viruses [35], and catalyze cleavage of a wide diversity of substrates. In addition to boosting the activity of hydrolytic enzymes for nutrient acquisition, LPMOs have also recently been implicated in other biological roles, including plant defense [36] and microbial copper acquisition and virulence [37].

Cellulomonas bacteria have historically been key model systems for cellulase research. Cellulomonas fimi in particular has attracted research interest since the late 1960s, when it was first shown to be capable of completely saccharifying pretreated sugarcane bagasse [38]. Subsequently, the cellulases and hemicellulases of $C$. fimi have been the subject of early gene cloning, recombinant expression, and detailed mechanistic and structural studies, which have significantly informed the broader field of glycosidase and carbohydrate-binding module research [9-14, 39-65]. Despite this rich history, whole-genome sequences of $C$. fimi and C. flavigena only became available in the past decade [66, 67], revealing that these species encode large and diverse collections of glycoside hydrolases (see http://www.cazy.org/b1637 .html and http://www.cazy.org/b1235.html for current censuses) [68]. A recent proteomic analysis [5] has subsequently identified key components of the C. fimi and C. flavigena secretomes, and further indicated that these bacteria encode one and four predicted LPMOs from AA10, respectively, which were previously uncharacterized. Genomic analysis $[66,67]$ indicates that all of the C. flavigena AA10-encoding genes are surrounded by diverse, unrelated CAZyme-encoding genes, while the sole AA10-encoding gene from C. fimi is not proximal to any known CAZyme-encoding genes.
Here, we describe the comprehensive biochemical characterization of four cellulolytic AA10 LPMOs from C. fimi and C. flavigena: CfiLPMO10, CflaLPMO10A, CflaLPMO10B, and CflaLPMO10C (nomenclature according to ref. [58]). We demonstrate the substrate specificity and regioselectivity of each LPMO using enzyme kinetic and product analysis by HPLC and mass spectrometry. The thermostability of each LPMO was investigated and evidence is presented concerning the critical role that copper ligand binding plays in enabling refolding following thermal denaturation. In addition, we examined the morphological effects of LPMO activity on cellulose surfaces using transmission and scanning electron microscopy. Finally, through activity progress curves, we demonstrate that the distinct LPMOs encoded by $C$. flavigena play synergistic roles in cellulose breakdown.

\section{Results}

Primary sequence analysis of Cellulomonas catalytic modules

All Cellulomonas LPMOs are multi-modular proteins containing a SEC pathway secretion signal peptide, a catalytic AA10 module, and a C-terminal CBM2 that is indicative of cellulose or chitin binding [45, 69-71]. Pairwise sequence alignment of the AA10 modules indicated that the single C. fimi ortholog, CfiLPMO10, was most similar to CflaLPMO10B (74\% sequence identity, $80 \%$ sequence similarity, Additional file 3: Table S1). Among the C. flavigena LPMOs, CflaLPMO10B and CflaLPMO10C were the most similar to each other $(60 \%$ pairwise identity, $71 \%$ similarity). Notably, CflaLPMO10D, encoded by Cfla_0490, was the most distinct sequence, sharing ca. $30 \%$ pairwise similarity and $20 \%$ pairwise identity with all of the other Cellulomonas AA10 members.

Multiple sequence analysis and Maximum-Likelihood phylogenetic analysis with all characterized AA10 LPMOs presently listed in the CAZy database revealed the likely substrate specificities of each Cellulomonas AA10 member. CfiLPMO10, CflaLPMO10A, CflaLPMO10B, and CflaLPMO10C segregated into a predominantly cellulose-specific clade, whereas CflaLPMO10D clustered within an exclusively chitin-active clade (Fig. 1). These clades correspond to Clade I and Clade II, respectively, as described by Book et al. [72]. In addition, CflaLPMO10A further segregated into a subclade of C1-regiospecific cellulose-active LPMOs, including Thermobifida fusca LPMO10B [73], Streptomyces coelicolor LPMO10C [74], and Streptomyces ambofaciens LPMO10C [75]. On the other hand, CfiLPMO10, CflaLPMO10B, and CflaLPMO10C segregated into a subclade comprising cellulose-active LPMOs possessing both 


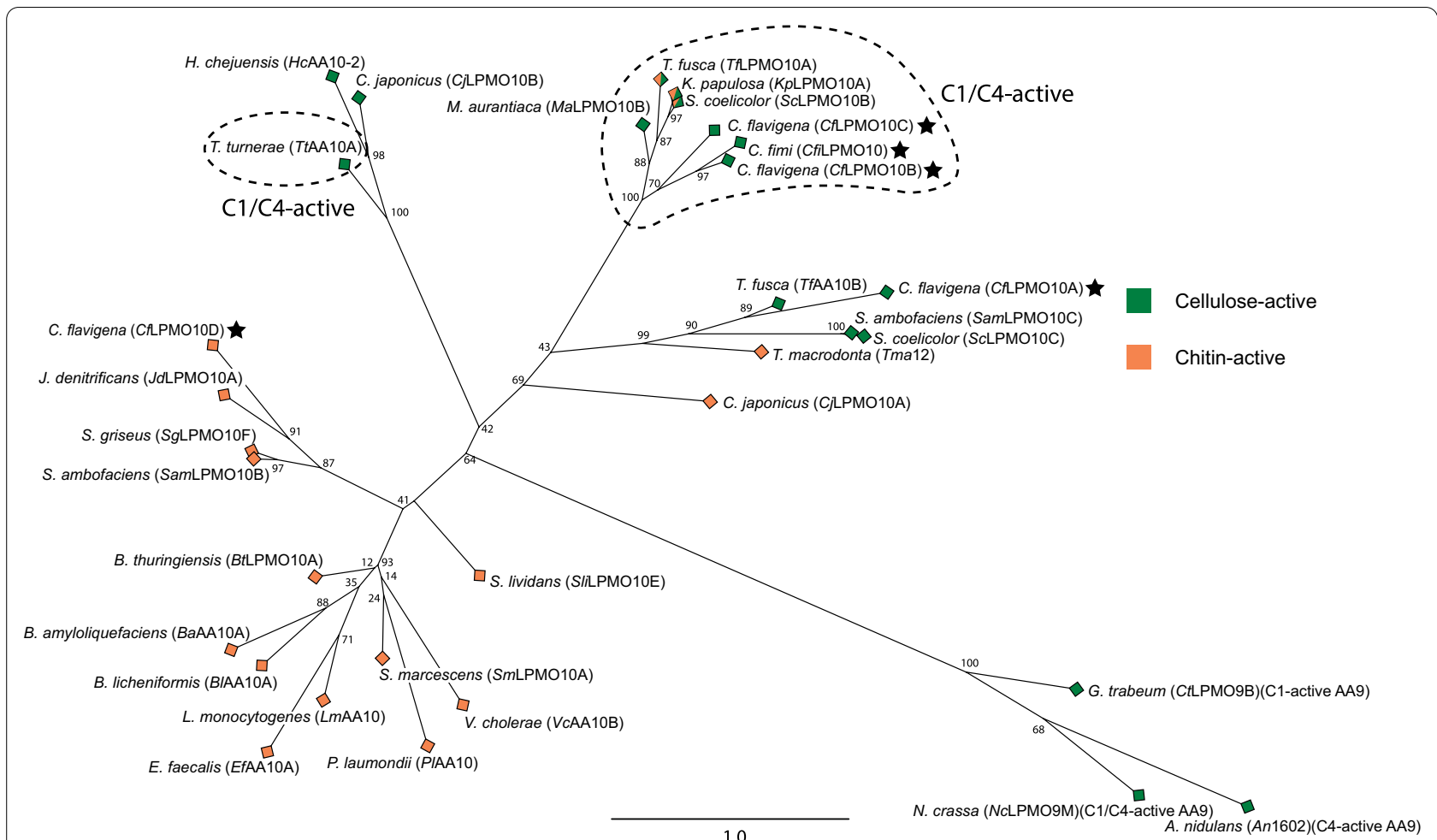

Fig. 1 Maximum-likelihood phylogenetic tree of all currently characterized AA10 LPMO catalytic modules. Full-length protein sequences were retrieved from GenBank via the CAZy database and manually truncated to remove the signal peptide and C-terminal domains (guided in part by SignalP and BLASTP analysis). The catalytic sequences were then aligned using MUSCLE and manually refined to preserve the position of the catalytic residues prior to maximum-likelihood analysis using RAXML 8.2.10 utilizing a JTT matrix-based nucleotide substitution model and automatic halting bootstraps (702 bootstraps). Three characterized AA9 LPMO catalytic module sequences with different regioselective activities on chitin were used as outgroups (GtLPMO9B [131], AN1602 [132], and NCLPMO9D [133]). The input and output files are provided as Additional file1: S1 and Additional file2: S2

C1-hydroxylating and C4-dehydrogenating activity, including Thermobifida fusca LPMO10A [73], Streptomyces coelicolor LPMO10B [74], and Micromonospora aurantiaca LPMO10B [76]. All copper-binding LPMOs contain a conserved histidine brace motif [77-79] presented on the substrate-interacting face of an Immunoglobulin-like/Fibronectin III-like beta-sandwich fold comprising 7-9 beta strands [31, 32, 80].

The Phyre ${ }^{2}$ server [81] was used to generate tertiary structure homology models of the four Cellulomonas LPMO catalytic modules, which clearly revealed the conserved beta-sandwich fold (Fig. 2 and Additional file 3: Figure S2). The sequence between strands $\beta 1$ and $\beta 3$ of AA10 LPMOs ( $\beta 1$ and $\beta 2$ in AA9s) contains a highly variable region of loops and helices, termed the L2 region, which has been shown to be important in substrate binding and recognition [23, 80, 82, 83]. CfiLPMO10, CflaLPMO10A, CflaLPMO10B, and CflaLPMO10C all contained a long L2 region comprising a cellulose-binding signature motif [23, 84] (Fig. 2e). In contrast, CflaLPMO10D contained a slightly shorter L2 region with a distinct chitin-binding signature motif [23, 84] (Additional file 3: Figure S2). Within these signature motifs, the first, second, and fourth residues have been shown to be critical in substrate recognition and regioselectivity [29, 85-88] (Fig. 2e). The first aromatic residue, predominantly Trp in cellulolytic AA10 members and Tyr in chitinolytic AA10 members, is located on the binding face and was shown through molecular dynamic simulations [85, 87] and NMR [29] to participate in stacking interactions with cognate substrates. The residue directly adjacent is a strictly conserved Asn or Glu in cellulose- and chitin-active AA10 LPMOs, respectively [88]. CfiLPMO10, CflaLPMO10A, CflaLPMO10B, and CflaLPMO10C each contain Asn at this position, whereas CflaLPMO10D contains Glu (Fig. 2). The fourth residue of the specificity signature motif is Phe or Gln in strict C1-regiospecific cellulose- and chitin-active AA10 LPMOs [88], and Asn in mixed C1/C4 celluloseactive AA10 LMPOs [88] which corroborated with our multiple sequence analysis (Additional file 3: Figure S3). CfiLPMO10, CflaLPMO10B, and CflaLPMO10C each 
contain Asn at this position (Fig. 2b-d), while CflaLPMO10D contains Gln (Additional file 3: Figure S2A). Notably, CflaLPMO10A contains a Tyr at this position (Additional file 3: Fig. 2a), which may be structurally and functionally homologous to Phe. In addition, only CflaLPMO10A was found to contain a Glu at position 185 , which was shown to be highly conserved in strict C1-oxidizing cellulose-active AA10 enzymes [78, 89], whereas the other LPMOs have a Gln at this position.

Taken together, these bioinformatic analyses suggest that CfiLPMO10, CflaLPMO10A, CflaLPMO10B, and CflaLPMO10C are likely to be cellulose-active, whereas CflaLPMO10D is likely to be chitin-active. Notably, secretomic analysis of $C$. fimi and C. flavigena revealed that the production of CfiLPMO10, CflaLPMO10A, CflaLPMO10B, and CflaLPMO10C were all upregulated when grown on carboxymethyl cellulose (CMC) [5]. Hence, we selected the four putative celluloseactive LPMOs for recombinant production and further characterization.

\section{Recombinant production of Cellulomonas LPMOs}

The four putative cellulose-active LPMOs (CflaLPMO10A, CflaLPMO10B, CflaLPMO10C, and $C f i L P M O 10)$ each contain a secretory signal peptide that is predicted to target these proteins to the SEC pathway [90]. cDNA encoding the AA10 modules, including the native SEC secretion signal peptide, of CfiLPMO10, CflaLPMO10A, CflaLPMO10B, and CflaLPMO10C, was cloned from genomic DNA with the addition of a C-terminal $\mathrm{His}_{6}$ purification tag and transformed into $E$. coli for expression. Secretion of LPMO proteins through the SEC pathway in E. coli has previously resulted in accumulation of recombinant protein in the periplasm $[91,92]$ and the culture medium $[93,94]$, with the former necessitating periplasmic fractionation. We observed that the majority of the recombinant Cellulomonas LPMOs were found in the media, with negligible amounts in the periplasm. Thus, all targets were subsequently purified from the cell-free supernatant without the need of mechanical lysis and soluble fraction separation. Following immobilized metal affinity chromatography, production in shake flasks yielded 1-2 mg of soluble CfiLPMO10, CflaLPMO10B, and CflaLPMO10C per liter of culture medium and 5-10 $\mathrm{mg}$ of CflaLPMO10A per liter of culture medium. Protein purity was verified by polyacrylamide gel electrophoresis (Additional file 3: Figure S4), and confirmation of the correct processing of the signal peptide to generate the critical $\mathrm{N}$-terminus histidine was confirmed through intact protein mass spectrometry (Additional file 3: Figure S1; CflaLPMO10A residues 1-204, calc. Mr 23639.9 Da, obs. Mr 22,273 Da, corresponding to a loss of SAAAALEHH$\mathrm{HHHH}$ at the C-terminus; $C f \mathrm{LPMO} 10 \mathrm{~B}$ residues 1-239, calc. $M r 22822.2 \mathrm{Da}$, obs. $M r 22822.0 \mathrm{Da}$; $C f \mathrm{LPMO} 10 \mathrm{C}$ residues 1-204, calc. $M r 22741.9 \mathrm{Da}$, obs. $M r 22740.0 \mathrm{Da}$; and CfLPMO10 residues 1-203, calc. $M r 22810.3 \mathrm{Da}$, obs. Mr 22808.0 Da).

\section{Substrate specificity}

The canonical substrates of LPMOs are insoluble cellulose and chitin, although some LPMOs have been shown to be active on soluble hemicelluloses and starch [23]. Thus, the activities of the purified Cellulomonas LPMOs were initially screened against a large panel of polysaccharide and oligosaccharide substrates in an overnight $(16 \mathrm{~h})$ end-point assay under aerobic conditions using ascorbic acid as the reductant. CfiLPMO10, CflaLPMO10A, CflaLPMO10B, and CflaLPMO10C were all active on insoluble cellulosic substrates, including microcrystalline cellulose (Avicel), phosphoric acid-swollen cellulose (PASC), bacterial cellulose (BC) from Komagataeibacter xylinus (also known as Acetobacter xylinum or Gluconacetobacter xylinus), Northern Bleached Softwood Kraft Pulp (NBSKP), as well as cellulose nanocrystals (CNC) and cellulose nanofibrils (CNF) derived from NBSKP. Representative product profiles from enzyme incubations with PASC determined by HPLC are shown in Fig. 3. No activity was observed on chitin, chitosan, tamarind xyloglucan, barley mixed-linkage $\beta$-glucan, carboxymethyl cellulose, hydroxyethyl cellulose,

\footnotetext{
(See figure on next page.)

Fig. 2 Homology models and primary sequence alignment of Cellulomonas LPMO catalytic modules. a-d Cartoon representation of three-dimensional homology models of CflaLPMO10A, CflaLPMO10B, CflaLPMO10C, and CfiLPMO10, respectively, generated using the Phyre ${ }^{2}$ server with T. fusca LPMO10A as the template structure [81]. The active-site histidine residues are depicted as orange sticks, the three conserved residues of the cellulose-active motif are depicted as yellow sticks, the axial tyrosine or phenylalanine residues are depicted as turquoise or pink sticks, respectively, and the catalytic glutamate or glutamine residues are depicted as teal sticks. Residue numbering corresponds to His-1 in the mature protein sequence. The L2 region is colored red to distinguish it from the immunoglobulin-like $\beta$-sandwich core colored in green. e Sequence and secondary structure alignment of Cellulomonas LPMOs compared to T. fusca LPMO10A [73]. The cellulose-active motif is indicated by a green dotted box and the positioning of the conserved residues mentioned in-text are numbered 1-3. The two active site histidine residues are indicated with black star symbols. The red dotted box with star indicates the position of the axial aromatic residue. The position of the catalytic glutamate or glutamine is indicated with a teal star
} 


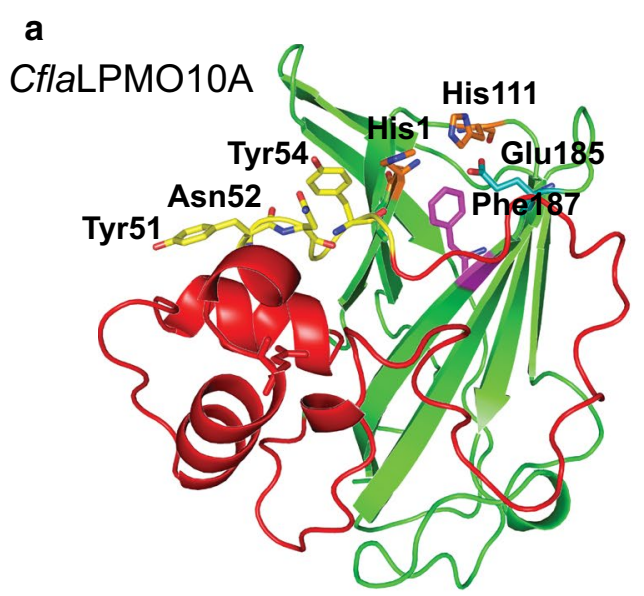

b

CflaLPMO10B

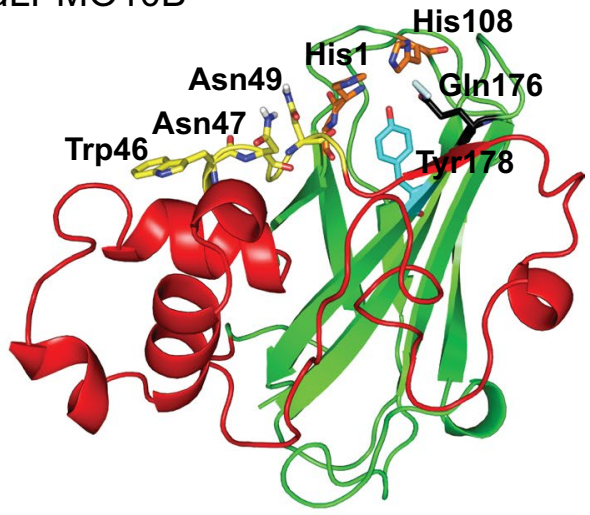

C

d

CflaLPMO10C

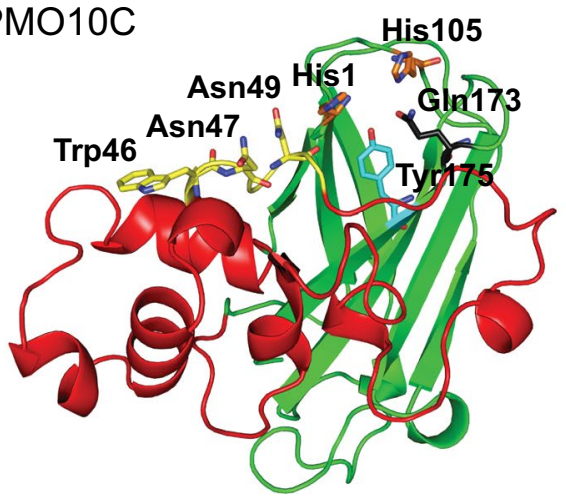

CfiLPMO10

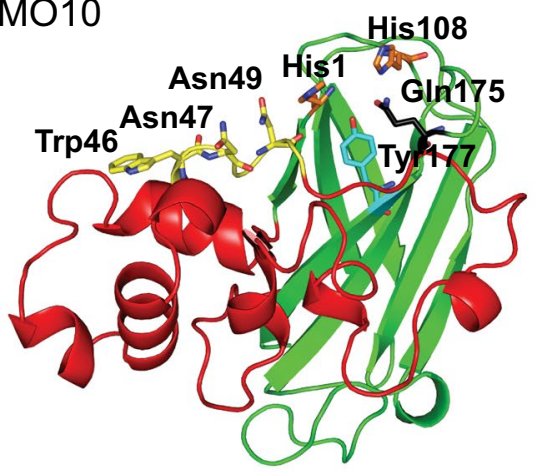

e
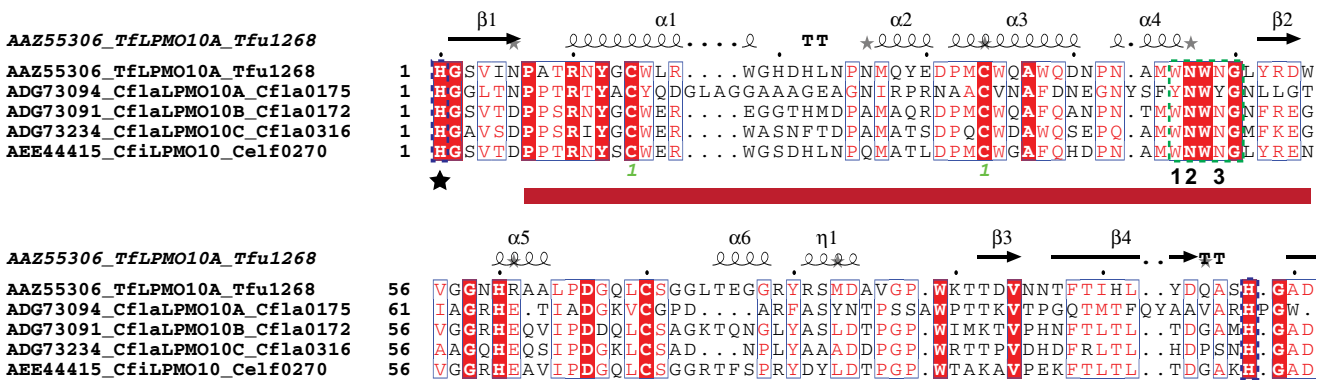

AAZ55306_TfLPMO10A_TfU1268 ADG73094 Cf ADG7 991_CflaLPMO10B_Cfla017 AEE 44415_CfiLPMO10_Celf0270

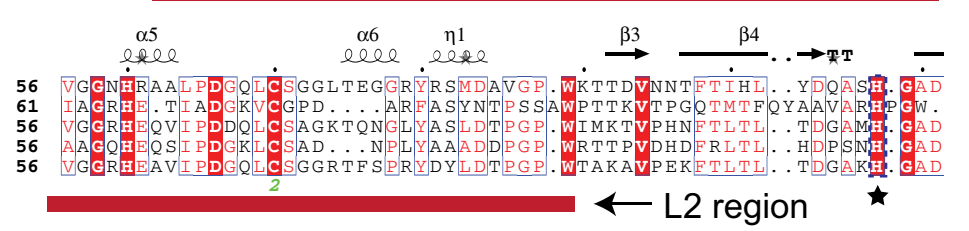

AAZ55306_TFLPMO10A_Tfu1268 AAZ55306_TfLPMO10A_Tfu1268 ADG73094_Cf1aLPMO10A_Cfla0175 ADG73234 ADG73234_CflaLPMO10C_Cfla03

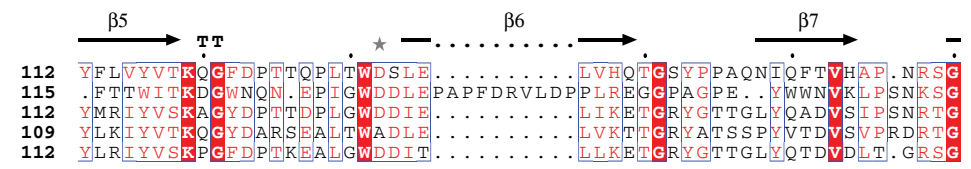

AAZ55306_TfLPMO10A_Tfu1268 AAZ55306_TfLPMO10A_Tfu1268 ADG73094_CflaLPMO10A_Cfla0175 171 RHVLFNIWERTDSPESFYNCVDVDFGGG

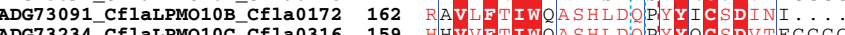
AEE44415_CfiLPMO10_Celf0270 161 RAVIETIWQASHLDOPIYYCSINVGT T 


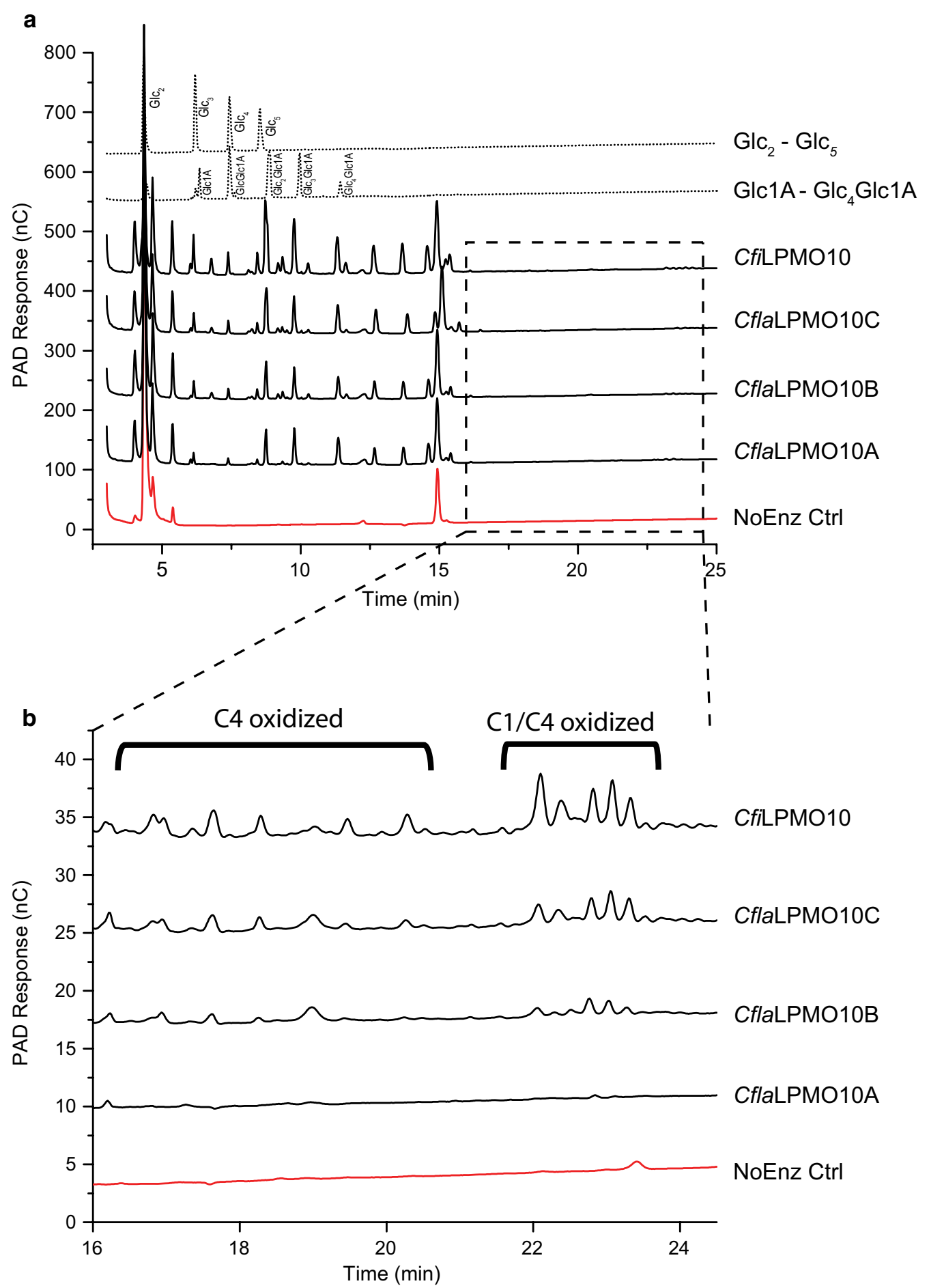

Fig. 3 HPAEC-PAD analysis of Cellulomonas LPMO activity on PASC. a Chromatogram over the retention times 3-25 min $\mathbf{b}$ Expansion of the 16-24 min region. Native and C1-oxidized cello-oligosaccharide standard peaks are annotated. All activity assays were conducted using $1 \mu \mathrm{M}$ of enzyme, $0.1 \%$ PASC, and $1 \mathrm{mM}$ ascorbic acid over $16 \mathrm{~h}$ at $37^{\circ} \mathrm{C}$. The negative control (NoEnz Ctrl) contained all assay components except enzyme 
beechwood xylan, curdlan, starch, glucose, and soluble cello-oligosaccharides $\left(\mathrm{Glc}_{2}\right.$ through $\left.\mathrm{Glc}_{6}\right)$.

Initial analysis of the product profiles by HPLC of the action of the four Cellulomonas LPMOs on cellulosic substrates, as exemplified by PASC, clearly showed the production of C1-oxidized cello-oligosaccharides (Fig. 3a), for which standard samples were readily produced. By analogy with previous studies [74, 76, 95], the presence of peaks of longer retention time (>16 min), suggested the possibility of additional $\mathrm{C} 4$ and mixed $\mathrm{C} 1 /$ C4-oxidized products (Fig. $3 \mathrm{~b}$ ) in the assay supernatant of CfiLPMO10, CflaLPMO10B, and CflaLPMO10C. To confirm the ability of these Cellulomonas LPMOs to catalyze $\mathrm{C} 4$ oxidation, the released soluble products were analyzed by MALDI-TOF MS. Consistent with the HPLC data, the mass spectrum evidenced products with $m / z$ values corresponding to $\left[\mathrm{M}+\mathrm{Na}^{+}\right]$adducts of $\mathrm{Glc}_{5}-\mathrm{Glc}_{8}$ cello-oligosaccharides and their C1-oxidized counterparts (Fig. 4). Specifically, pseudomolecular ions with $+16 \mathrm{~m} / z$ and $-2 \mathrm{~m} / z$ were also observed, which were consistent with the aldonic and lactone forms of C1-oxidized cello-oligosaccharides (Fig. 4e, f). Mass spectra of the products of CfiLPMO10, CflaLPMO10B, and $C$ flaLPMO10C also evidenced products with pseudomolecular ions of $-4 \mathrm{~m} / z$, which corresponds to doubly oxidized $\mathrm{C} 1$ aldonic acid/C4 ketoaldose oligosaccharides (Fig. 4e); C4 ketoaldose oligosaccharides are isobaric with $\mathrm{C} 1$-oxidized lactones and are thus indistinguishable by MS. Together, the HLPC and MS data demonstrate that all four Cellulomonas LPMOs predominantly catalyze C1 regioselective oxidation of cellulose. Whereas CflaLPMO10A appears to be C1 regiospecific, CfiLPMO10, CflaLPMO10B, and CflaLPMO10C are also capable of $\mathrm{C} 4$ oxidation. These results are consistent with the regioselectivity predicted in the phylogenetic analysis.

To simplify quantitation by HPLC, soluble C1-oxidized products were hydrolyzed using a cellulolytic cocktail to glucose, cellobiose, and cellobionic acid. The peak corresponding to cellobionic acid was then used to approximate Cellulomonas LPMOs activity after $16 \mathrm{~h}$ incubations with Avicel, PASC, BC, NBSKP, $\mathrm{CNC}$, and CNF. Avicel and PASC, in particular, represent commonly used model cellulose substrates of differing morphologies: Avicel, which is produced by acid hydrolysis of wood pulp, is a representative Cellulose I (parallel microfibrillar) substrate with a low surface area and high crystallinity index (ca. 60\% [96]). PASC is produced by phosphoric acid treatment of Avicel, which yields Cellulose II (antiparallel microfibrils) with a high surface area to volume ratio and a relatively low degree of crystallinity (ca. 30\% [97]) [95, 96, 98100]. As shown in Fig. 5, all four Cellulomonas LPMOs are most active on PASC $(30-70 \mu \mathrm{M}$ of oxidized products after $16 \mathrm{~h}$ ). For all of the LPMOs, substrates with higher degrees of crystallinity and/or lower surface area, e.g., Avicel and $\mathrm{CNC}$, were the poorest substrates. $\mathrm{BC}$ and $\mathrm{CNF}$ were intermediate as substrates, likely due to higher surface areas; $\mathrm{BC}$ is extruded as fine ribbons [101] and CNF is mechanically fibrillated from NBSKP. Interestingly, industrially relevant wood pulp fibers (NBSKP) were the poorest substrates for the LPMOs, and activity was only detected at very high substrate loadings (1\% NBSKP vs $0.1 \%$ for all other substrates). CfiLPMO10 exhibited the highest activity of all four LPMOs across the entire range of cellulose substrates, while the three $C$. flavigena homologs exhibited comparable activities to each other.

Both oxygenase $\left(\mathrm{O}_{2}\right.$ cosubstrate $)[102,103]$ and peroxygenase $\left(\mathrm{H}_{2} \mathrm{O}_{2}\right.$ cosubstrate) [104] activity have been reported for individual LPMOs. Hence, each Cellulomonas LPMO was assayed for the ability to utilize hydrogen peroxide as a cosubstrate in both aerobic and anaerobic conditions. CflaLPMO10A was the only enzyme for which peroxygenase activity was measurable (Additional file 3: Figure S5). Under anaerobic conditions (i.e., with $100 \mu \mathrm{M} \mathrm{H}_{2} \mathrm{O}_{2}$ as the sole cosubstrate and $1 \mathrm{mM}$ ascorbic acid as the reductant), a rapid burst of activity in the first minute of reaction was observed; however, this activity quickly ceased at $10 \mathrm{~min}$. Under aerobic conditions, the addition of $\mathrm{H}_{2} \mathrm{O}_{2}$ likewise resulted in an initial increase in the rate of cellobionic acid production, but again rapid inactivation was observed, suggesting that CflaLPMO10A succumbs to oxidative damage more rapidly in the presence of peroxide. In light of these results, all further quantitative

\footnotetext{
(See figure on next page.)

Fig. 4 MALDI-TOF product analysis of Cellulomonas LPMO activity on PASC. a-d Mass spectrum of $\mathrm{m} / \mathrm{z} 800-1600$ showing native and oxidized cello-oligosaccharide products between $\mathrm{DP}_{5}-\mathrm{DP}_{8}\left[\mathrm{M}+\mathrm{Na}^{+}\right]$released by the Cellulomonas $\mathrm{LPMO}$ indicated above each respective panel. $\mathbf{e}, \mathbf{f}$ Representative expanded mass spectra of $\mathrm{m} / \mathrm{z}$ 1000-1040 depicting DP 6 [M+ Na ${ }^{+}$peaks from CflaLPMO10A and CflaLPMO10B corresponding to native, C1-, and mixed C1/C4-oxidized cello-oligosaccharides. $\mathbf{g}$ Symbols used to denote native and oxidized cello-oligosaccharide products corresponding to peaks in mass spectra. Red stars are monosodiated aldonic and lactone forms of C1-oxidized cello-oligosaccharides. Pink stars are monosodiated native cello-oligosaccharides; teal stars are monosodiated doubly oxidized C1 aldonic acid/C4 ketoaldose oligosaccharides; green stars are monosodiated aldonic acid forms of C1-oxidized cello-oligosaccharides; and black stars are disodiated aldonic acid forms of C1-oxidized cello-oligosaccharides
} 

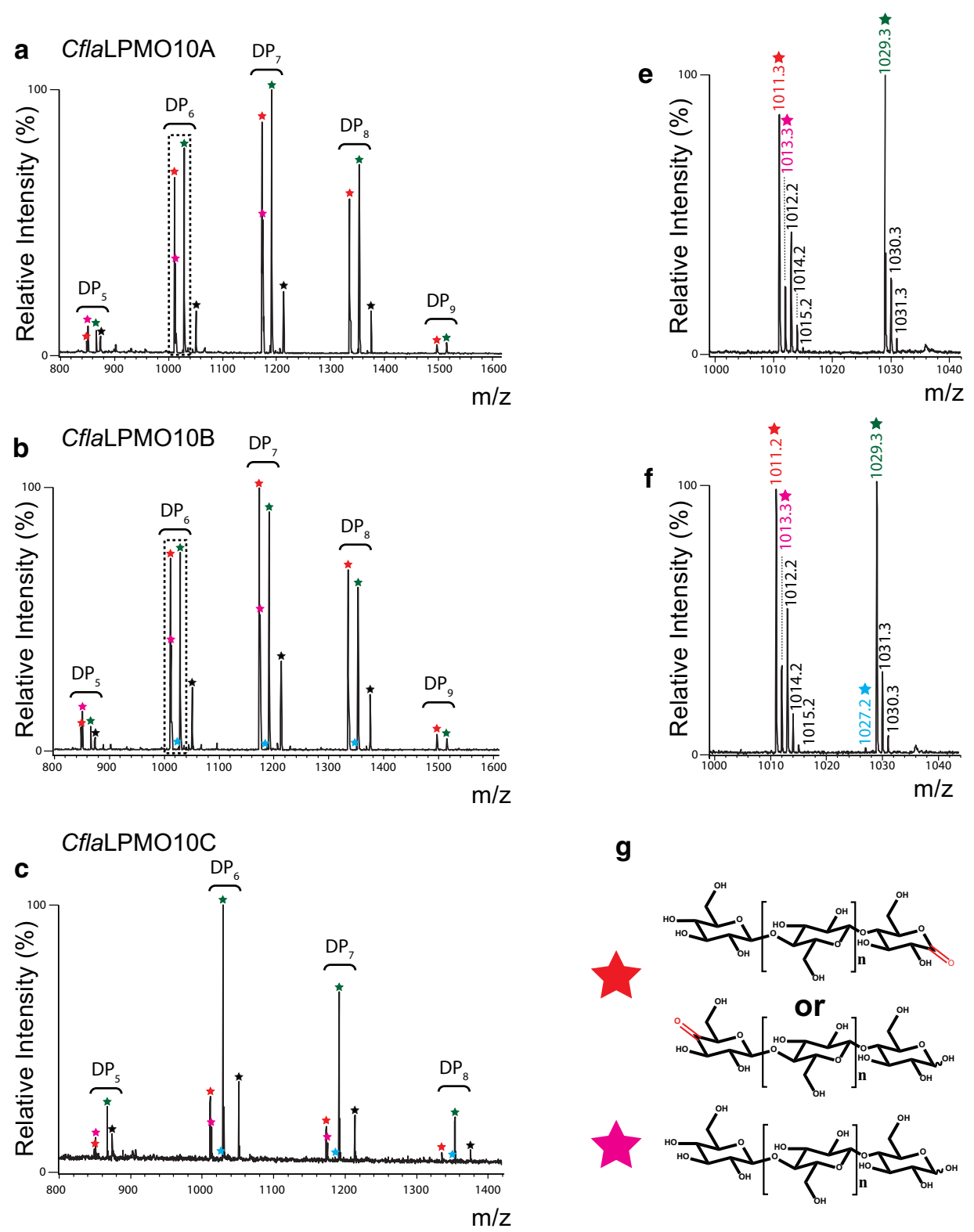

g

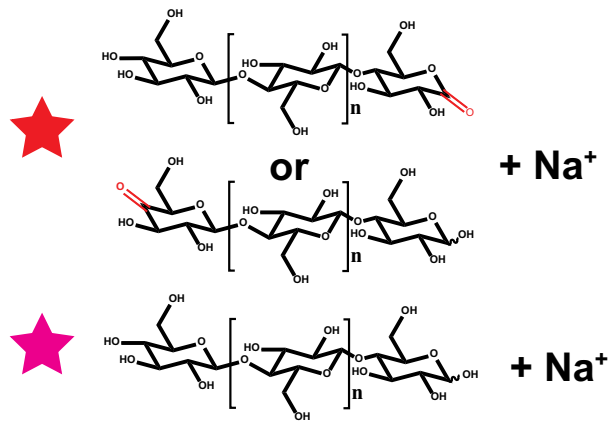

d CfilPMO10
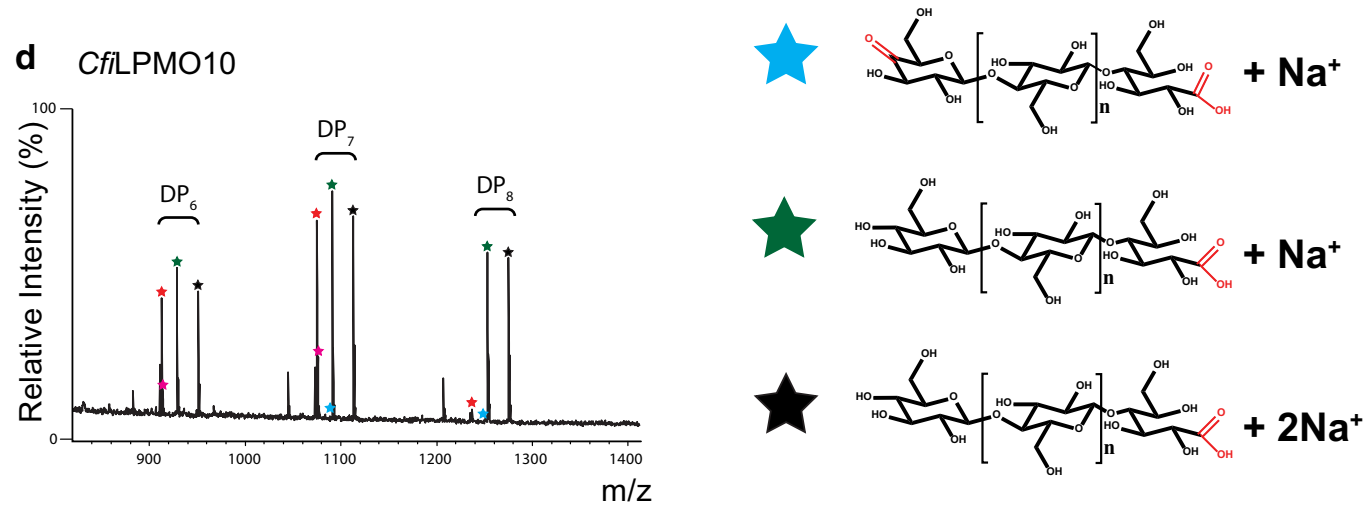


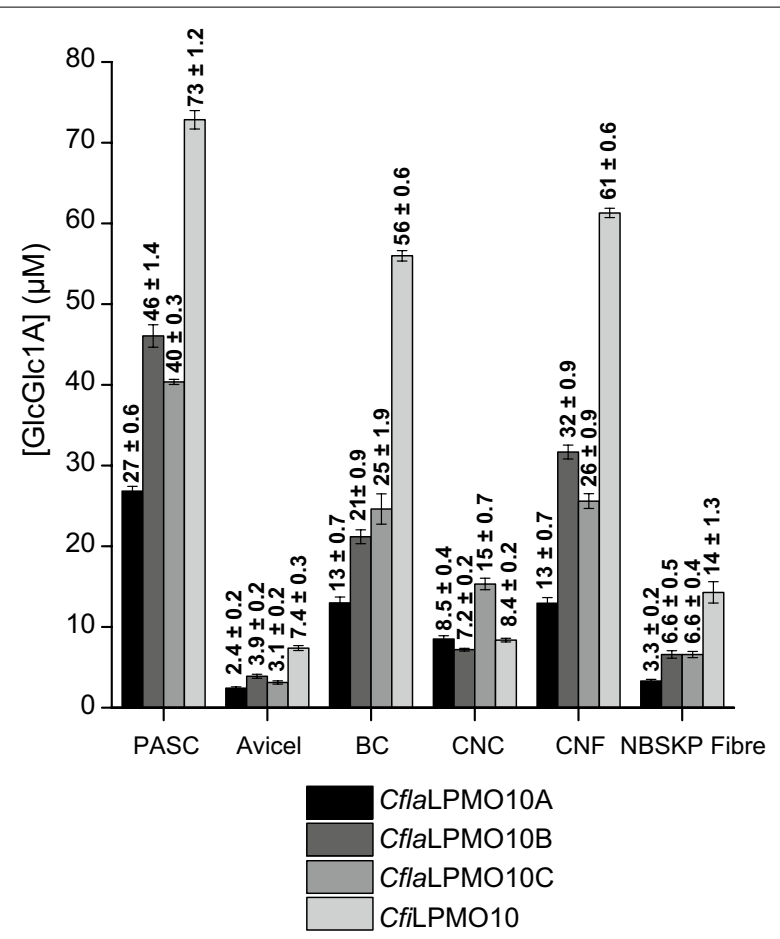

Fig. 5 C1-oxidized ends produced by $1 \mu$ M Cellulomonas LPMOs after $16 \mathrm{~h}$ on a panel of insoluble cellulose substrates. All substrates were assayed at $0.1 \%$ except NBSKP fiber which was assayed at $1 \%$ (no activity was detected at $0.1 \%$ NBSKP fiber). For each substrate, T. reesei cellulase cocktail (Celluclast; Sigma-Aldrich, P/N: C2730-30) was used to convert all C1-oxidized products into cellobionic acid and quantified as the total $\mathrm{C} 1$-oxidized ends generated $(\mu \mathrm{M})$. Total oxidized ends were obtained by quantifying cellobionic acid by HPLC following hydrolysis of soluble products with T. reesei Celluclast enzyme cocktail. Each time point represents the average of three independent assays measured singly by HPLC, with error bars indicating the standard error of the mean

LPMO assays were performed aerobically, with ambient molecular oxygen as the sole cosubstrate.

\section{pH Dependence and thermostability}

All four cellulose-active Cellulomonas LPMOs remained catalytically active between $\mathrm{pH} 4.5$ and 10.5 and were generally difficult to inactivate. Indeed, as exemplified by CflaLPMO10A, activity was generally observed to be undiminished after boiling for $30 \mathrm{~min}$ or after addition of high concentrations of ammonium hydroxide $(0.5 \mathrm{M})$ at room temperature. Only the addition of EDTA at room temperature led to a loss of activity (Additional file 3: Figure S6). To investigate the basis of this high temperature and $\mathrm{pH}$ stability, a Thermofluor analysis $[105,106]$ was used to assess the melting temperature of Cellulomonas LPMOs at various $\mathrm{pH}$ conditions. Each Cellulomonas LPMO was shown to unfold at around $45-55^{\circ} \mathrm{C}$ in the storage buffer $20 \mathrm{mM}$ Tris- $\mathrm{HCl}, \mathrm{pH}$ 8. For all four enzymes, it was generally observed that the highest melting temperatures were at neutral to alkaline $\mathrm{pH}$, with a reduction of melting temperatures below $\mathrm{pH} 5$ (Additional file 3: Figure S7A-7D). Thermofluor analysis also indicated that all four Cellulomonas LPMOs were able to refold following cooling at room temperature, as evidenced by $T_{\mathrm{m}}$ values from repeat melting curves. Subsequently, differential scanning calorimetry (DSC) of CflaLPMO10A at various $\mathrm{pH}$ conditions confirmed that the protein melting temperature was essentially unchanged at neutral to alkaline $\mathrm{pH}$ following repeated temperature cycling (Additional file 3: Figure S8).

The ability to regenerate active enzymes by refolding was confirmed by assaying each LPMO for the production of oxidized $\mathrm{Glc}_{4}-\mathrm{Glc}_{6}$ oligosaccharides before and after boiling. (CflaLPMO10A was fully active following cooling, whereas CflaLPMO10B, CflaLPMO10C, and CfiLPMO10 retained ca. $70-80 \%$ of their initial activity (Additional file 3: Table S2). The apparent inability of the LPMOs to refold at low $\mathrm{pH}$ is likely due to protonation of active-site histidines, which would interfere with copper coordination. Indeed, when copper was chelated with D-penicillamine (DPA) in the Thermofluor analysis, we were unable to observe a second melting curve (Additional file 3: Figure S7E-G) following cooling to allow spontaneous refolding with any of the LPMOs at $\mathrm{pH} 8$. Notably, the presence of DPA did not significantly affect the melting temperature of LPMOs during the first heating cycle, suggesting that copper was not likely to have been extracted from the holoenzymes. Taken together these results clearly demonstrate the critical effect of bound copper ligand on the thermal stability of LPMOs.

\section{Effect of cellulose morphology on LPMO activity and stability}

After establishing the cellulose specificity and regioselectivity of the four Cellulomonas LPMOs, we sought further insight into the effect of substrate morphology on enzyme activity and stability using Avicel and PASC as model crystalline and amorphous substrates, respectively.

As introduced above (Fig. 5), all four cellulolytic Cellulomonas LPMOs exhibited a much higher activity on PASC than Avicel under standard conditions containing $0.1 \% \mathrm{w} / \mathrm{v}$ substrate in suspension (Additional file 3: Figure S9a). In detailed time course experiments, CfiLPMO10, CflaLPMO10A, CflaLPMO10B, and CflaLPMO10C all rapidly lost activity over the course of the $16 \mathrm{~h}$ assay with both Avicel and PASC (Additional file 3: Figure S9a; $c f$. Additional file 3: Figure S5 for CflaLPMO10A). Supplementation with additional substrate and ascorbic acid could not rescue activity and demonstrated that activity loss was caused by enzyme inactivation rather than 


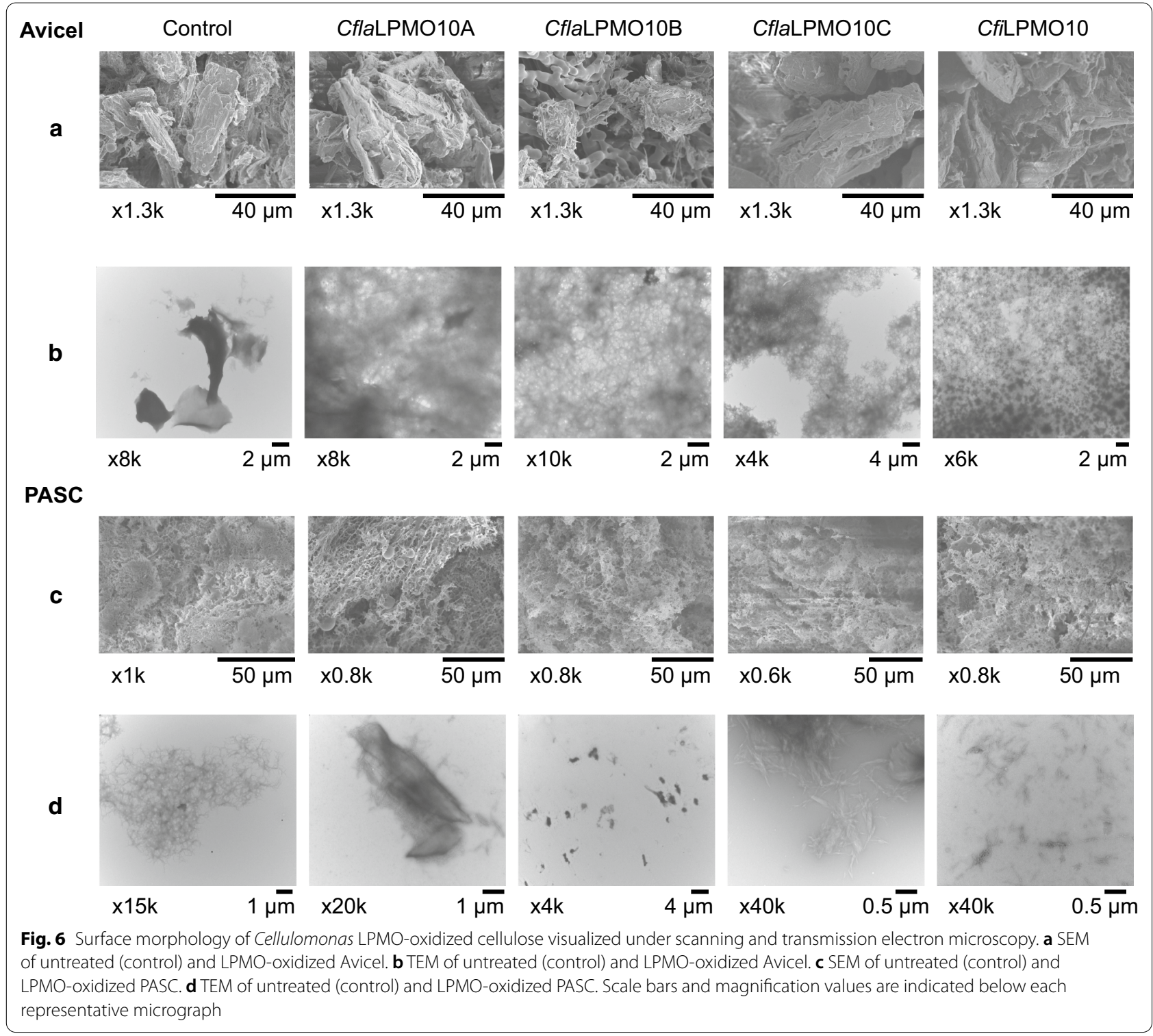

substrate or reducing agent availability (Additional file 3: Figure S10). Such inactivation is known to be caused by oxidative damage via futile generation of reactive $\mathrm{H}_{2} \mathrm{O}_{2}$ in the absence of suitable surface area for LPMO binding and catalytic turnover [104]. In keeping with this, inclusion of a tenfold higher concentration of substrate, i.e., $1 \%(\mathrm{w} / \mathrm{v})$ PASC, greatly prolonged the activity of CflaLPMO10A (Additional file 3: Figure S9b). CflaLPMO10C demonstrated the highest initial activity, generating ca. a twofold higher concentration of oxidized products than any of the other LPMOs at $10 \mathrm{~min}$, yet this also coincided with inactivation by $30 \mathrm{~min}$. Notably, only CfiLPMO10 appeared to be immune to inactivation and continued to generate oxidized products over the entire course of the $16 \mathrm{~h}$ incubation. These phenomena were consistently observed at different total enzyme loadings $0.25 \mu \mathrm{M}-1 \mu \mathrm{M}$ (Additional file 3: Figure S11).

Analysis of soluble products presents only limited insight into the oxidative activity of LPMOs on insoluble cellulosic surfaces. Thus, electron microscopy was used to examine changes in cellulose morphology following LPMO oxidation on Avicel and PASC under identical conditions to those used for quantitative HPLC assays. SEM of untreated Avicel reveals cellulose particles with an estimated size between 40 and $50 \mu \mathrm{m}$ and a rough surface morphology (Fig. 6a). Under TEM, Avicel appears to be tightly compacted with little particulate dispersion in the aqueous medium (Fig. 6b). Despite comparatively 
slow release of soluble products in the HPLC-based assays, EM analysis clearly evidenced changes in Avicel morphology with all four LPMOs. A general softening of surface features was observed by SEM, especially for $C f i \mathrm{LPMO} 10$ and CflaLPMO10B, concordant with oxidative perturbation of the cellulose surface yielding partially disintegrated, amorphous cellulose. Correspondingly, TEM analysis of LPMO-treated Avicel also demonstrated disintegration of the Avicel particles, as indicated by larger areas containing dispersed, nanocellulosic structures in the aqueous medium. This phenomenon was particularly evident in samples treated with CfiLPMO10 or CflaLPMO10B, concordant with the SEM analysis.

In contrast, the surface of PASC was expectedly composed of very fine cellulose nanofibers and nanoaggregates, which form a thin film structure upon drying. Thus, differences in the surface morphology before and after LPMO oxidation were difficult to distinguish by SEM (Fig. 6c). However, TEM images of LPMO-treated PASC (Fig. 6d) clearly depict the formation of scattered, dense structures indicative of nanofibers in comparison to untreated PASC. These data suggest that the four Cellulomonas LPMOs may preferentially attack less-ordered regions of cellulose before addressing the more recalcitrant crystalline nanostructures.

\section{LPMO combinatorial synergy}

To better understand why $C$. flavigena maintains multiple LPMO-encoding genes within its genome, while C. fimi only encodes one, these enzymes were assayed in combination to assess their capacity to collectively boost (or hinder) cellulose degradation. Specifically, LPMOs were assayed on PASC in combinations of two, three, and four using HPLC time course measurements over $16 \mathrm{~h}$. The resulting progress curves show that $C$. flavigena enzymes, in any combination of equal proportions, can effectively boost the release of oxidized products on PASC (Fig. 7). In addition, $C$. flavigena combinations were more active than any individual enzyme at equivalent enzyme loadings. For example, $0.33 \mathrm{uM}$ of each of the three C. flavigena LPMOs released more oxidized products than $1 \mu \mathrm{M}$ of any individual C. flavigena enzyme (Additional file 3: Figure S12d). Furthermore, the observed boosting effect was noticed to be a result of delayed enzyme inactivation ( $c f$. Figure 7 and Additional file 3: Figure S12), as demonstrated by the continuation of oxidized product release up to (and likely beyond) $16 \mathrm{~h}$. As an example, when all three $C$. flavigena LPMOs are combined at equal concentrations (total enzyme loading of $1 \mu \mathrm{M}$ or $0.33 \mu \mathrm{M}$ of each enzyme), the quantified concentration of released oxidized product after $16 \mathrm{~h}$ was $55 \mu \mathrm{M}$. The independent additive release of $0.33 \mu \mathrm{M}$ of each enzyme on PASC was found to be $45 \mu \mathrm{M}$; an increase of just over $20 \%$ in oxidative activity (Additional file 3: Fig. 12Sd). This trend is observed at both higher and lower enzyme loadings, suggesting that this synergistic effect is independent of enzyme concentration (Fig. 7). The same trends are not observed when $C f$ LPMO10 is combined with any of the C. flavigena LPMOs. Rather, the addition of any C. flavigena LPMO with CfiLPMO10 did not result in prolonged activity, and an overall decrease of soluble oxidized products was observed after $16 \mathrm{~h}$ (Additional file 3: Figure S13).

\section{Discussion}

Bacteria from the genus Cellulomonas, and Cellulomonas fimi in particular, are historically significant organisms in cellulase research [9-14, 39-65, 68]. Here, we have used detailed biochemical analysis to define CflaLPMO10A as a cellulose-active LPMO with strict $\mathrm{C}-1$ specificity (EC 1.14.99.54). In contrast, CfiLPMO10, CflaLPMO10B, and CflaLPMO10C cleaved cellulose at $\mathrm{C} 1$ of glucosyl residues in the cellulose chain but also had some capacity to affect cleavage by oxidation at C4 (EC 1.14.99.56). To our knowledge, there has been no AA10 LPMO characterized with exclusive $C 4$ regiospecificity [23], so this may represent a side activity of these three Cellulomonas LPMOs. Indeed, the low concentration of C4-oxidized products detected indicates that this activity may be a consequence of incidental cleavage at this position.

Our initial primary structural analysis and homology modeling correctly predicted the substrate specificity and regiospecificity of these enzymes. Of note, we observed that the first aromatic residue within the substrate recognition motifs on the L2 loop (either Tyr or Trp in Cellulomonas LPMOs) corresponds to a pattern indicative of regioselectivity. At this position, strict $\mathrm{C} 1$-active AA10s have a Tyr residue, while mixed C1/C4-active AA10s have a tryptophan. To our knowledge, this pattern has not been previously reported. Possible exceptions are

\footnotetext{
(See figure on next page.)

Fig. 7 Progress curves of released soluble oxidized products by C. flavigena LPMOs incubated in combination and independently. a-d Double and triple combinations of C. flavigena enzymes incubated together at a total enzyme loading of $1 \mu \mathrm{M}$ compared to the sum total of the independent enzyme proportions at $1 \mu \mathrm{M}$. e-g Boosting effect of a combined mixture of all three C. flavigena LPMOs at three different enzyme loading concentrations vs the sum total of independent enzyme proportions at each respective total enzyme load. Total oxidative activity was quantified from simplification of the product profile to cellobionic acid using T. reesei cellulase cocktail as described in the results and each assay was performed independently and in triplicate to calculate standard error of the mean
} 

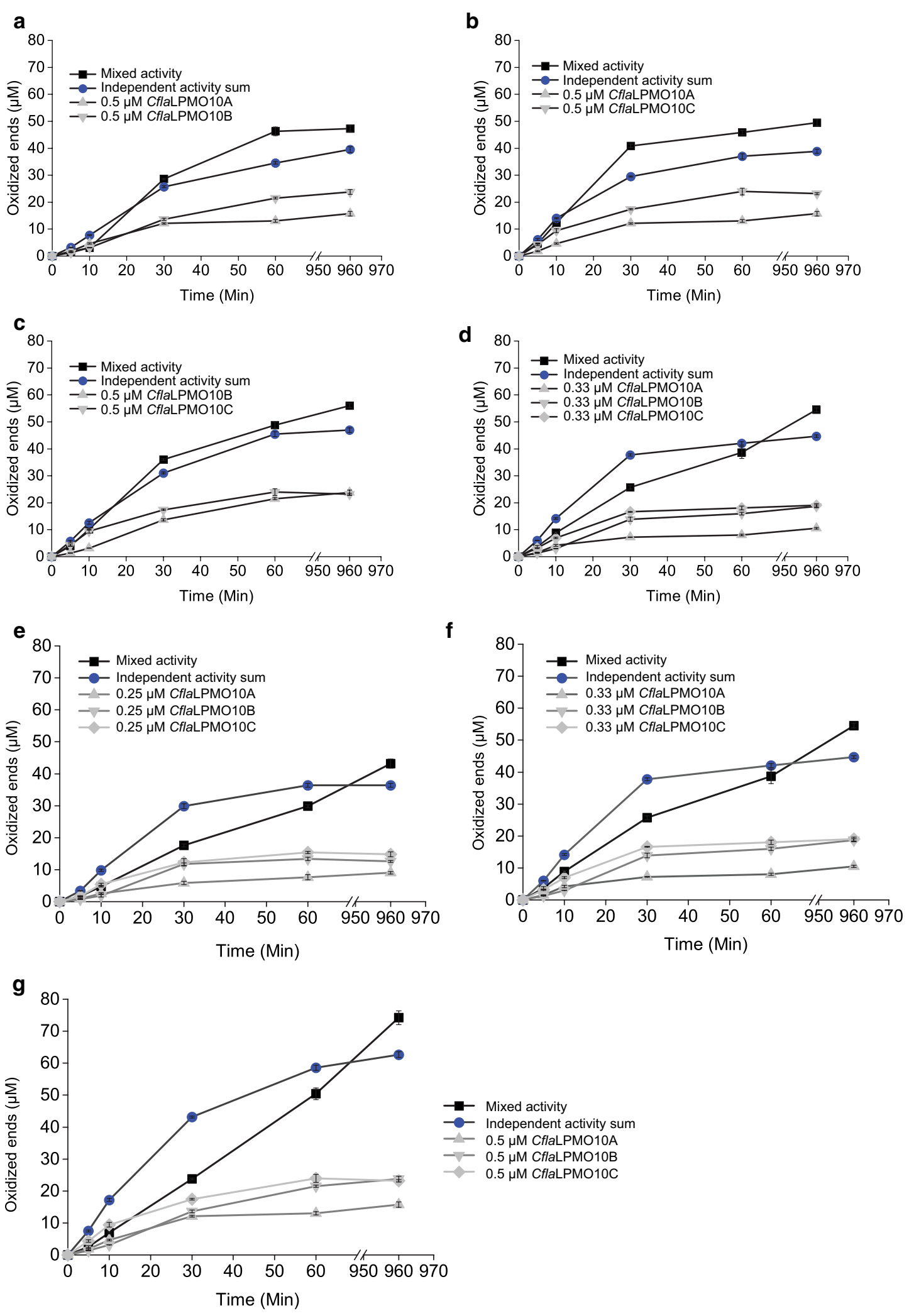
TtLPMO10A, which contains a Tyr but was reported to have mixed $\mathrm{C} 1 / \mathrm{C} 4$ activity [73], and $K p$ LPMO10A, which has a Trp and was reported to have both mixed regioselectivity and activity on both cellulose and chitin [107]. In addition, a similar trend was observed concerning the axial aromatic residue at the active site (Phe or Tyr) [103, 108]. We observed that whereas C1-active AA10 LPMOs contain an axial Phe (regardless of cellulose or chitin specificity), mixed C1/C4-active AA10 LPMOs possess a Tyr at this position. Again, the only exceptions to this pattern among characterized AA10 members are TtLPMO10A and KpLPMO10A [73, 107].

There has recently been significant interest in the identification of thermostable LPMOs, with a particular focus on fungal AA9 members [109, 110]. Interestingly, the cellulolytic LPMOs from the mesophiles C. fimi and C. flavigena studied here proved to be only moderately thermostable, with $\mathrm{pH}$-dependent $T_{\mathrm{m}}$ values in the range of $40-60{ }^{\circ} \mathrm{C}$ (Additional file 3: Figure S6), yet difficult to inactivate by boiling. Further analysis revealed a strong propensity of these proteins to refold spontaneously following thermal denaturation, which was mediated by the presence of copper ions. Bound copper has been previously associated with modulation of LPMO thermostability [111-114]; given the high affinity of the histidine brace for its ligand, this may nucleate protein refolding. Although the Cellulomonas LPMOs are unlikely to find application in sustained high-temperature bioprocesses, their ability to renature upon cooling does not preclude their application to biomass at elevated temperatures followed by cooling.

The analysis of Cellulomonas LPMO activity on a panel of cellulosic substrates generally suggested a preference for substrates with high surface area and lower crystallinity. Furthermore, it appears that the stability of these LPMOs is inversely correlated with the rate of catalytic turnover and, by extension, of the potential for futile cycling leading to hydrogen peroxide generation. For example, CflaLPMO10C had the highest initial activity on both PASC and Avicel of the four LPMOs; however, it also succumbed most rapidly to enzyme inactivation.

Many cellulolytic microbes are known to encode multiple LPMOs in their genomes [92, 115, 116], although the biological reasons for this are not well understood. Previous studies on this topic have focused on understanding LPMO regulation by polysaccharide substrates [5, 117], and certainly LPMOs with distinct activity profiles toward cellulose, hemicellulose, and other polysaccharides have been identified [23-29]. The need to produce multiple LPMOs of apparently similar activity is less obvious, but as for hydrolytic cellulases, there is some evidence for functional synergy among these enzymes [92]. Likewise, our combinatorial LPMO experiments demonstrated synergy between the three C. flavigena LPMOs. Strikingly, synergy between these LPMOs was not observed in any combination with the lone C. fimi LPMO10; thus, all cellulolytic LPMOs-even from closely related species - are not created equal. The production of multiple LPMOs in response to specific substrates is not a simple gene dosage phenomenon, but rather serves to deliver a suite of complementary enzymes acting together to enable more efficient saccharification of recalcitrant paracrystalline cellulose.

We did not pursue the characterization of the remaining AA10 member from C. flavigena because our bioinformatic analysis strongly indicated that this protein is likely to be a chitin-active LPMO (EC 1.14.99.53) and was thus outside the scope of this study. Nonetheless, we note that facultative chitin utilization by a Cellulomonas bacterium was previously reported [118], and that the genomes of C. flavigena and C. fimi encode putative chitin-targeting GH23 and CBM50 members. By analogy with the comprehensive study of cellulolytic $\mathrm{GH}$ and LPMO in Cellulomonas species, exploration of the full hydrolytic and oxidative chitin-degrading system of these bacteria is worthy of future pursuit.

\section{Conclusions}

The comprehensive elucidation of the specificity and mechanism of the complete repertoire of carbohydrateactive enzymes encoded by an organism (the "CAZome") is essential to fully understand the roles that an environmental microorganism fulfills in the global carbon cycle. The present study advances understanding of the cellulose utilization machinery of historically important $\mathrm{Cel}$ lulomonas species beyond hydrolytic enzymes to include lytic cleavage of the world's most abundant biopolymer. Additionally, this work contributes to the broader mapping of enzyme activity in Auxiliary Activity Family 10 and provides new biocatalysts for potential applications in biomass modification.

\section{Materials and methods \\ Bioinformatic analyses}

Full-length protein sequences of biochemically characterized LPMO enzymes were obtained from GenBank via hyperlinks in the CAZy database [68] (http://www. cazy.org/AA10_characterized.html) and were aligned using BLASTP to identify C. fimi and C. flavigena AA10 catalytic module boundaries. Following truncation to remove predicted carbohydrate-binding modules (CBM) or other domains at the $\mathrm{C}$ termini, the Cellulomonas AA10 sequences were aligned with those of the characterized AA10 members and three characterized AA9 sequences (comprising an outgroup) using MUSCLE [119] within MEGA [120] and manually realigned to 
preserve structurally homologous residues (Additional file 1). A maximum-likelihood phylogeny (Additional file 2) was subsequently generated using RAXML 8.2.10 within the CIPRES Science Gateway v3.1 [121] with the following settings: JTT matrix-based nucleotide substitution model [122] of 25 discrete rate categories and rapid bootstrapping with automatic halting enabled ( 702 bootstraps). Figtree was used to visualize the resulting phylogenetic tree (http://tree.bio.ed.ac.uk/software/figtree). Three-dimensional homology models were generated using Phyre $^{2}$ [81].

\section{Gene cloning and protein production}

cDNA encoding the native signal peptide and catalytic domain of CflaLPMO10A (encoded by genome locus Cfla_0175, GenBank accession ADG73094.1), CflaLPMO10B (encoded by genome locus Cfla_0172, GenBank accession ADG73091.1), CflaLPMO10C (encoded by genome locus Cfla_0316, GenBank accession ADG73234.1), and CfiLPMO10 (encoded by genome locus Celf_0270, GenBank accession AEE44415.1) were amplified from gDNA of Cellulomonas flavigena DSM 20,109 and Cellulomonas fimi ATCC 484, respectively. PCR products were purified from agarose gel using a Qiaquick Gel Extraction Kit (Qiagen, Hilden, Germany, $\mathrm{P} / \mathrm{N}: 28,115)$. The cDNA were subsequently inserted into pET29b(+) vectors using NdeI/Xhol sites for CfiLPMO10 (Celf_0270) and CflaLPMO10B (Cfla_0172) and NdeI/NotI sites for CflaLPMO10A (Cfla_0175) and CflaLPMO10C (Cfla_0316) using restriction enzymes purchased from NEB (Ipswitch, MA, P/N: R0111, R0146, and R0189 for NdeI, XhoI and NotI, respectively). Correctly cloned constructs were verified by Sanger sequencing (GENEWIZ).

All four pET constructs were transformed into Rosetta $^{\mathrm{TM}}$-(DE3) pLysS E. coli cells (Millipore Sigma, Oakville, ON Canada, P/N: 70,956). Protein expression was induced in LBE-5052 autoinduction medium [123] containing $50 \mu \mathrm{g} / \mathrm{ml}$ kanamycin (Millipore Sigma, $\mathrm{P} / \mathrm{N}: 10106801001$ ) and $35 \mu \mathrm{g} / \mathrm{ml}$ chloramphenicol (Millipore Sigma, P/N: C1919) and grown in shake flasks for $26 \mathrm{~h}$ at $25^{\circ} \mathrm{C}$ at $250 \mathrm{rpm}$. Media were then centrifuged at $18,600 \times g$ for 20 min at $4{ }^{\circ} \mathrm{C}$ in a Beckman Coulter Avanti J-E Highspeed Centrifuge (Brea, CA, USA). The supernatant was collected and treated with Roche $1 \mathrm{X}$ cOmplete, Mini EDTA-free Protease Inhibitor cocktail (Millipore Sigma, P/N: COEDTAF-RO) and concentrated to $20 \mathrm{ml}$ using a 10,000 kDa cut-off Vivaflow 200 PES membrane from Sartorius (Göttingen, Germany, P/N: VF20PO). The $\mathrm{pH}$ of the concentrated supernatant was adjusted to 8 using $\mathrm{NaOH}$, filtered through a $0.22 \mu \mathrm{m}$ PES membrane and injected on a $1 \mathrm{ml} \mathrm{Ni-NTA}$ prepacked column from GE Healthcare (Chicago, IL, USA, P/N: 17-5247-01) pre-equilibrated in binding buffer $(20 \mathrm{mM}$ Tris- $\mathrm{HCl} \mathrm{pH}$ $8,500 \mathrm{mM} \mathrm{NaCl}$ and $10 \mathrm{mM}$ imidazole). The column was subsequently washed with $10 \mathrm{~mL}$ of binding buffer and mature His-tagged LPMO proteins were eluted using a linear gradient of 0 to $100 \%$ elution buffer $(20 \mathrm{mM}$ Tris$\mathrm{HCl} \mathrm{pH} \mathrm{8,} 500 \mathrm{mM} \mathrm{NaCl}$, and $500 \mathrm{mM}$ imidazole) over $12 \mathrm{~min}$. The elution fractions were collected and incubated with $1 \mathrm{mM} \mathrm{CuCl}_{2}$ (Millipore Sigma, P/N: 222,011250G) for $1 \mathrm{~h}$ at room temperature and subsequently desalted via size-exclusion chromatography using a $16 \times 600 \mathrm{~mm}$ column of Sephadex G-25 (GE Healthcare, $\mathrm{P} / \mathrm{N}$ : 17003301) pre-equilibrated in storage buffer (20 mM Tris- $\mathrm{HCl}$ buffer $\mathrm{pH}$ 8), flash frozen in aliquots, and stored at $-70{ }^{\circ} \mathrm{C}$ until use. Protein fidelity was confirmed using intact protein MS, essentially as previously described [124]; correct cleavage of the signal peptide to yield the $\mathrm{N}$-terminal His-1 required for catalytic activity was observed in all cases; however, limited proteolysis of the C-terminus was observed for CflaLPMO10A and $C f i$ PMO10 (Additional file 1: Figure S1A and S1D).

\section{Carbohydrates}

Avicel, chitin, and chitosan substrates were purchased from Sigma Aldrich (St. Louis, MO, USA). Starch and glucose were purchased from Fisher Scientific (Hampton, NH, USA). Cellobiose was purchased from Acros Organic (Morris Plains, NJ, USA). Tamarind xyloglucan, barley mixed-linkage $\beta$-glucan, carboxymethyl cellulose, hydroxyethyl cellulose, beechwood xylan, curdlan, cellotriose, cellotetraose, cellopentaose, and cellohexaose were purchased from Megazyme International (Bray, Ireland). Northern bleached softwood Kraft pulp (NBSKP) was donated by Canfor Pulp (Vancouver, BC, Canada). Bacterial cellulose was grown and harvested from Komagataeibacter xylinus (i.e., Acetobacter xylinum, Gluconacetobacter xylinus) following a previously published protocol [125]. Cellulose nanocrystals (CNC) were produced from acid hydrolysis of NBSKP and cellulose nanofibrils (CNF) were produced from NBSKP by lowconsistency refining at the UBC Pulp and Paper Centre. Phosphoric acid-swollen cellulose (PASC) was prepared from Avicel following a previously published protocol [126].

C1-oxidized cello-oligosaccharide standards were prepared using Podospora anserina cellobiose dehydrogenase $(\mathrm{CDH})$, kindly provided by Dr. Jean Guy Berrin (INRA, Marseilles, France) [127]. $1 \mu \mathrm{M}$ of $\mathrm{CDH}$ was added to a $2 \mathrm{mM}$ of each cello-oligosaccharide $\left(\mathrm{Glc}_{2}-\right.$ $\mathrm{Glc}_{5}$ ) in $50 \mathrm{mM}$ sodium acetate buffer, $\mathrm{pH} 5$, followed by incubation at $50{ }^{\circ} \mathrm{C}$. Full conversion was achieved by supplementation of additional enzyme every $24 \mathrm{~h}$ for 3 days. 


\section{Protein denaturation analysis}

Thermofluor denaturation assays were performed in 7500 Fast Real-Time PCR system (Applied Biosystems) based on a previously published protocol [128]. MicroAMP Fast Reaction 8-strip tubes (Thermo Fisher, Waltham, MA, USA, P/N: 4358293) and strip caps (Thermo Fisher, P/N: 4323032) were used as reaction vessels in which $5 \mu \mathrm{M}$ enzyme was incubated with $20 \mathrm{mM}$ of appropriate buffer solution and SYPRO Orange diluted to a final 10X concentration from a 5000X stock as supplied by the manufacturer (Invitrogen, Carlsbad, CA, USA, P/N: S6650). $1 \mathrm{mM}$ D-penicillamine (Alfa Aeser, Heysham, Lankashire, UK, P/N: A11446) was used for copper chelation experiments. Thermal denaturation curves were produced by first holding the reaction at $10^{\circ} \mathrm{C}$ for $6 \mathrm{~min}$ followed by a constant ramp rate of $0.85{ }^{\circ} \mathrm{C}$ per minute (1\%) until $95{ }^{\circ} \mathrm{C}$ and held for $1 \mathrm{~min}$ followed by a final drop to $10{ }^{\circ} \mathrm{C}$ and held for $10 \mathrm{~min} .7500$ Software v.2.3 (Applied Biosystems) was used to collect fluorescence data.

Differential scanning calorimetry (DSC) experiments were performed on a Microcal ${ }^{\mathrm{TM}}$ VP-Capillary DSC (Malvern Panalytical, Westborough, MA, USA) based on a previously published protocol [129]. $20 \mu \mathrm{M}$ enzyme in $200 \mu \mathrm{L}$ containing appropriate buffers $(50 \mathrm{mM}$ sodium acetate $\mathrm{pH} 3.5,50 \mathrm{mM}$ BisTris $\mathrm{pH} 5,50 \mathrm{mM}$ BisTris $\mathrm{pH} 7$, and $50 \mathrm{mM}$ glycine $\mathrm{pH} 10$ ) were degassed under vacuum for $10 \mathrm{~min}$ before loading into sample cell (cell volume $133 \mu \mathrm{L}$ ). Background scans were performed prior to each experiment using buffer blanks to generate normalized data. The calorimeter was programmed to ramp to $100{ }^{\circ} \mathrm{C}$ at a scan rate of $60{ }^{\circ} \mathrm{C}$ per hour before cooling to $10{ }^{\circ} \mathrm{C}$ and holding for $30 \mathrm{~min}$ before starting the second scan. Data analysis and curve fitting were performed using Origin Pro software.

\section{LPMO activity assay}

The oxidation of insoluble cellulosic substrates by $\mathrm{Cel}$ lulomonas LPMOs was performed at $37^{\circ} \mathrm{C}$ with shaking at $1000 \mathrm{rpm}$ in an Eppendorf Thermomixer C (Hamburg, Germany) for up to $16 \mathrm{~h}$. Typical assays were performed in $300 \mu \mathrm{L}$ with $0.1 \% \mathrm{w} / \mathrm{v}$ substrate using $50 \mathrm{mM}$ citrate-BSA buffer, containing $0.02 \%$ bovine serum albumin (VWR, Radnor, PA, USA, P/N: 97061-420). $1 \mathrm{mM}$ ascorbic acid (Fisher Bioreagents, P/N: B351) was added last to start the reaction and enzymatic reactions were stopped by the removal of substrate via centrifugal filtration through $0.2 \mu \mathrm{m}$ cellulose acetate spin filters (VWR, $\mathrm{P} / \mathrm{N}$ : 2994-752). For peroxidase activity assays, $100 \mu \mathrm{M}$ of hydrogen peroxide was added at the start of the experiment. Soluble oxidized oligosaccharides were subsequently detected via High-Performance Anion-Exchange Chromatography coupled with Pulsed Amperometric Detection (HPAEC-PAD) as described below. For quantification of LPMO activity, T. reesei cellulase cocktail (Celluclast, Sigma-Aldrich, P/N: C2730-30) was used to hydrolyze released soluble cello-oligosaccharides into glucose, cellobiose, and cellobionic acid (note: gluconic acid was not observed in these hydrolyzed samples). Total oxidation activity was calculated from quantification of oxidized cellobionic acid through standard calibration curves. In general, 1 unit of Celluclast was added to 100 $\mu \mathrm{L}$ of LPMO assay supernatant and incubated at room temperature for $1 \mathrm{~h}$ before analysis by HPAEC-PAD.

\section{Product analysis by HPAEC-PAD}

Soluble cello-oligosaccharides and corresponding oxidation products were analyzed by HPAEC using an ICS5000 system (Dionex, Sunnyvale, CA, USA) coupled to a gold electrochemical detector (Dionex, P/N: 072044) for PAD. The oligosaccharide separation methodology was designed based on a previously published protocol [130]: $25 \mu \mathrm{L}$ of sample were injected on a CarboPac PA200 $2 \times 250 \mathrm{~mm}$ analytical column (Dionex, P/N: 062896) with a CarboPac PA200 $2 \times 50 \mathrm{~mm}$ guard (Dionex, P/N: 062895) column maintained at $30{ }^{\circ} \mathrm{C}$. Oligosaccharide separation was achieved at a constant flow rate of $0.5 \mathrm{~mL} /$ $\mathrm{min}$. Initial column equilibration for $10 \mathrm{~min}$ with an isocratic flow of $0.1 \mathrm{M} \mathrm{NaOH}$, followed by a linear gradient toward $0.25 \mathrm{M} \mathrm{NaOAc}$ over $30 \mathrm{~min}$ and then a stepwise increase to $0.9 \mathrm{M} \mathrm{NaOAc}$ for $1 \mathrm{~min}$ as a column cleaning step.

\section{Product analysis by MALDI-MS}

Matrix-assisted laser desorption/ionization time-of-flight (MALDI-TOF) mass spectrometry was performed using a matrix of $9 \mathrm{mg} / \mathrm{ml}$ 2,5-dihydroxybenzoic acid (DHB) (Sigma-Aldrich, P/N: 149357) dissolved in 0.2\% trifluoroacetic acid (TFA). $2 \mu \mathrm{L}$ of the DHB matrix was mixed with $2 \mu \mathrm{L}$ assay supernatant and placed on a Bruker MTP 384 ground steel MALDI plate (Bruker Daltonics, Bremen, Germany P/N: 8280784) and dried under a stream of air prior to data collection. Experiments were performed on a Bruker Daltonics Autoflex system (Billerica, MA, U.S.A.). The data acquired over the range of $m / z$ 0 to 3000 were collected in positive-ion mode by averaging 2000 laser shots using the lowest energy sufficient to obtain adequate signal-to-noise ratios.

\section{Electron microscopy}

Transmission electron microscopy (TEM) samples were first prepared by drop casting $2 \mu \mathrm{L}$ of enzymatic reactions containing $0.025 \%$ of cellulose substrate on a 200 mesh carbon-coated copper TEM grid (TED PELLA, Inc., CA, USA). The grids were air dried at room temperature, followed by application of $5 \mu \mathrm{L}$ drops of aqueous uranyl acetate (2\%) to the dry grids. After $1 \mathrm{~min}$, 
the excess stain was removed by capillary action and gentle blotting, followed by air drying at room temperature. The negatively stained specimens were imaged using a Hitachi H7600 transmission electron microscope (Hitachi, Ltd., Tokyo, Japan) with an accelerating potential of $80 \mathrm{keV}$. Images were captured on a 5 MPAMT XR50 CCD camera (Advanced Microscopy Techniques Corp., MA, USA). The magnification bars on the images were calibrated using replica grating.

Scanning electron microscopy (SEM) samples were prepared by lyophilization of enzymatic reactions containing $0.1 \%$ cellulose substrate for $72 \mathrm{~h}$, followed by sputter coating with $10 \mathrm{~nm}$ of platinum or gold before imaging (108 auto/SE, Cressington Scientific Instruments, UK). Imaging was performed using a Hitachi S-4700 Field Emission scanning electron microscope (Hitachi, Ltd., Tokyo, Japan) with an accelerating potential of $5 \mathrm{keV}$.

\section{Supplementary Information}

The online version contains supplementary material available at https://doi. org/10.1186/s13068-020-01860-3.

Additional file 1: Multiple sequence alignment of LPMOs.

Additional file 2: Maximum-likelihood phylogenetic tree in Newick format.

Additional file 3: Additional figures and tables.

\section{Acknowledgements}

We thank Dr. Paul Bicho, Canfor Pulp, for providing NBSKP and for his support of this project. We thank Prof. James Olson (Mechanical Engineering, UBC) and colleagues for assistance with CNF production from NBSKP. J.L. thanks Dr. Louise Creagh (MSL, UBC) for training and assistance with DSC operation, Nicholas McGregor (Brumer group, MSL, UBC) for assistance with HPLC programming, and Hila Behar (Brumer group, MSL, UBC) for advice on phylogenetic analysis. The authors dedicate this article to Emeritus Professors Antony Warren, Douglas Kilburn, and Robert Miller, and Dr. Neil Gilkes, whose seminal work on multimodular cellulases and hemicellulases from Cellulomonas species at the University of British Columbia continues to inform broadly the fundamental study and biotechnological applications of carbohydrate-active enzymes.

\section{Authors' contributions \\ $J$ performed comparative bioinformatics, recombinant protein production, biochemical/biophysical studies including substrate screening, product analysis via HPLC and MALDI-TOF, protein denaturation studies, and combi- natorial synergy analysis. LS produced bacterial cellulose and CNF, assisted in recombinant protein production, and performed all microscopy analysis. EGB cloned all LPMO genes and performed initial recombinant expression trials. YM assisted in establishing LPMO assay conditions, product analysis via HPLC, and preparation of HPLC standards, and contributed expertise in recombinant protein production. HB, SGW, and WW conceived the study and supervised the research. JL drafted the manuscript, which was revised with HB. All the authors read and approved the final manuscript.}

\section{Funding}

This work was supported by grants to H.B. from the NSERC Strategic Partnership Grants for Projects program (STPGP 479088, F15-01751), and Genome Canada and GenomeBC (project \# 10405, "SYNBIOMICS—Functional genomics and techno-economic models for advanced biopolymer synthesis," www.synbi omics.ca).
Availability of data and materials

All data generated or analyzed during this study are included in this published article and its supplementary information files:

\section{Ethics approval and consent to participate}

Not applicable.

\section{Consent for publication}

Not applicable.

\section{Competing interests}

The authors declare that they have no competing interests.

\section{Author details}

${ }^{1}$ Michael Smith Laboratories, University of British Columbia, 2185 East Mall, Vancouver, BC V6T 1Z4, Canada. ${ }^{2}$ Department of Biochemistry and Molecular Biology, University of British Columbia, 2350 Health Sciences Mall, Vancouver, BC V6T 1Z3, Canada. ${ }^{3}$ Department of Chemistry, University of British Columbia, 2036 Main Mall, Vancouver, BC V6T 1Z1, Canada. ${ }^{4}$ Department of Biological Sciences, University of Alberta, Edmonton, AB T6G 2E9, Canada. ${ }^{5}$ Department of Botany, University of British Columbia, 3200 University Blvd, Vancouver, BC V6T 1Z4, Canada. ${ }^{6}$ BioProducts Institute, University of British Columbia, 2385 East Mall, Vancouver, BC V6T 1Z4, Canada.

Received: 7 October 2020 Accepted: 13 December 2020

Published online: 23 January 2021

\section{References}

1. Bidlack J, Malone M, Benson R. Molecular structure and component integration of secondary cell walls in plants. Proc Oklahoma Acad Sci. 1992;72:51-6.

2. Hanus J, Mazeau K. The xyloglucan-cellulose assembly at the atomic scale. Biopolymers. 2006;82(1):59-73.

3. Kubicek CP, Kubicek EM. Enzymatic deconstruction of plant biomass by fungal enzymes. Curr Opin Chem Biol. 2016;35:51-7.

4. Obeng EM, Adam SNN, Budiman C, Ongkudon CM, Maas R, Jose J. Lignocellulases: a review of emerging and developing enzymes, systems, and practices. Bioresour Bioprocessing. 2017. https://doi.org/10.1186/ s40643-017-0146-8.

5. Wakarchuk WW, Brochu D, Foote S, Robotham A, Saxena H, Erak T, Kelly J. Proteomic Analysis of the Secretome of Cellulomonas fimi ATCC 484 and Cellulomonas flavigena ATCC 482. PLoS ONE. 2016;11(3):e0151186.

6. Ma J, Zhang K, Liao H, Hector SB, Shi X, Li J, Liu B, Xu T, Tong C, Liu X, Zhu Y. Genomic and secretomic insight into lignocellulolytic system of an endophytic bacterium Pantoea ananatis Sd-1. Biotechnol Biofuels. 2016. https://doi.org/10.1186/s13068-016-0439-8.

7. Adav SS, Chao LT, Sze SK. Quantitative secretomic analysis of Trichoderma reesei strains reveals enzymatic composition for lignocellulosic biomass degradation. Mol Cell Proteomics. 2012;11(7):M111.012419.

8. Herpoël-Gimbert I, Margeot A, Dolla A, Jan G, Mollé D, Lignon S, Mathis $\mathrm{H}$, Sigoillot J-C, Monot F, Asther M. Comparative secretome analyses of two Trichoderma reesei RUT-C30 and CL847 hypersecretory strains. Biotechnol Biofuels. 2008. https://doi.org/10.1186/1754-6834-1-18.

9. O'Neill G, Goh SH, Warren RAJ, Kilburn DG, Miller RC Jr. Structure of the gene encoding the exoglucanase of Cellulomonas fimi. Gene. 1986;44(2-3):325-30.

10. Warren RAJ, Gerhard B, Gilkes NR, Owolabi JB, Kilburn DG, Miller RC $J$ r. A bifunctional exoglucanase-endoglucanase fusion protein. Gene. 1987;61(3):421-7.

11. Damude HG, Ferro V, Withers SG, Warren RAJ. Substrate specificity of endoglucanase A from Cellulomonas fimi: fundamental differences between endoglucanases and exoglucanases from family 6 . Biochemical Journal. 1996;315(2):467-72.

12. Meinke A, Braun C, Gilkes NR, Kilburn DG, Miller RC Jr, Warren RAJ. Unusual sequence organization in cenb, an inverting endoglucanase from Cellulomonas fimi. J Bacteriol. 1991;173(1):308-14.

13. Tomme P, Kwan E, Gilkes NR, Kilburn DG, Warren RAJ. Characterization of CenC, an enzyme from Cellulomonas fimi with both endo- and exoglucanase activities. J Bacteriol. 1996;178(14):4216-23. 
14. Meinke A, Gilkes NR, Kilburn DG, Miller RC, Warren RAJ. Cellulosebinding polypeptides from Cellulomonas fimi: endoglucanase D (CenD), a family A $\beta-1,4-$ glucanase. J Bacteriol. 1993;175(7):1910-8.

15. Béguin P. Molecular biology of cellulose degradation. Annu Rev Microbiol. 1990:44:219-48.

16. Park JI, Steen EJ, Burd H, Evans SS, Redding-Johnson AM, Batth T, Benke PI, D'haeseleer P, Sun N, Sale KL, Keasling JD, Lee TS, Petzold CJ, Mukhopadhyay A, Singer SW, Simmons BA, Gladden JM. A thermophilic ionic liquid-tolerant cellulase cocktail for the production of cellulosic biofuels. PLoS ONE. 2012;7(5):e37010.

17. Lopes AM, Ferreira Filho EX, Moreira LRS. An update on enzymatic cocktails for lignocellulose breakdown. J Appl Microbiol. 2018;125(3):632-45.

18. Yamada R, Hasunuma T, Kondo A. Endowing non-cellulolytic microorganisms with cellulolytic activity aiming for consolidated bioprocessing. Biotechnol Adv. 2013;31(6):754-63.

19. Hasunuma T, Kondo A. Development of yeast cell factories for consolidated bioprocessing of lignocellulose to bioethanol through cell surface engineering. Biotechnol Adv. 2012;30(6):1207-18.

20. Shaw AJ, Podkaminer KK, Desai SG, Bardsley JS, Rogers SR, Thorne PG, Hogsett DA, Lynd LR. Metabolic engineering of a thermophilic bacterium to produce ethanol at high yield. Proc Natl Acad Sci. 2008;105(37):13769-74.

21. Chung D, Cha M, Guss AM, Westpheling J. Direct conversion of plant biomass to ethanol by engineered Caldicellulosiruptor bescii. Proc Natl Acad Sci. 2014;111(24):8931-6.

22. Jeffries TW. Ethanol fermentation on the move. Nat Biotechnol. 2005:23(1):40-1.

23. Zhou $X$, Zhu H. Current understanding of substrate specificity and regioselectivity of LPMOs. Bioresour Bioprocess. 2020. https://doi. org/10.1186/s40643-020-0300-6.

24. Karkehabadi S, Hansson H, Kim S, Piens K, Mitchinson C, Sandgren $M$. The first structure of a glycoside hydrolase family 61 member, Cel61B from Hypocrea jecorina, at $1.6 \AA$ resolution. J Mol Biol. 2008;383(1):144-54

25. Harris PV, Welner D, MCFarland KC, Re E, Poulsen JCN, Brown K, Salbo R, Ding H, Vlasenko E, Merino S, Xu F, Cherry J, Larsen S, Lo Leggio L. Stimulation of lignocellulosic biomass hydrolysis by proteins of glycoside hydrolase family 61: structure and function of a large, enigmatic family. Biochemistry. 2010;49(15):3305-16.

26. Vaaje-Kolstad G, Westereng B, Horn SJ, Liu Z, Zhai H, Sorlie M, Eijsink VGH. An oxidative enzyme boosting the enzymatic conversion of recalcitrant polysaccharides. Science. 2010;330(6001):219-22.

27. Westereng B, Ishida T, Vaaje-Kolstad G, Wu M, Eijsink VGH, Igarashi K, Samejima M, Ståhlberg J, Horn SJ, Sandgren M. The putative endoglucanase PcGH61D from Phanerochaete chrysosporium is a metal-dependent oxidative enzyme that cleaves cellulose. PLoS ONE. 2011;6(11):e27807.

28. Forsberg Z, Vaaje-Kolstad G, Westereng B, Bunsæ AC, Stenstrøm Y, Mackenzie A, Sørlie M, Horn SJ, Eijsink VGH. Cleavage of cellulose by a CBM33 protein. Sci. 2011;20(9):1479-83.

29. Aachmann FL, Sørlie M, Skjåk-Bræk G, Eijsink VGH, Vaaje-Kolstad G. NMR structure of a lytic polysaccharide monooxygenase provides insight into copper binding, protein dynamics, and substrate interactions. Proc Natl Acad Sci. 2012;109(46):18799-18784.

30. Filiatrault-Chastel C, Navarro D, Haon M, Grisel S, Herpoël-Gimbert I, Chevret D, Fanuel M, Henrissat B, Heiss-Blanquet S, Margeot A, Berrin J-G. AA16, a new lytic polysaccharide monooxygenase family identified in fungal secretomes. Biotechnol Biofuels. 2019. https://doi. org/10.1186/s13068-019-1394-y.

31. Sabbadin F, Hemsworth GR, Ciano L, Henrissat B, Dupree P, Tryfona T, Marques RDS, Sweeney ST, Besser K, Elias L, Pesante G, Li Y, Dowle AA, Bates R, Gomez LD, Simister R, Davies GJ, Walton PH, Bruce NC, McQueen-Mason SJ. An ancient family of lytic polysaccharide monooxygenases with roles in arthropod development and biomass digestion. Nat Commun. 2018. https://doi.org/10.1038/s41467-018-03142-X.

32. Couturier M, Ladevèze S, Sulzenbacher G, Ciano L, Fanuel M, Moreau C, Villares A, Cathala B, Chaspoul F, Frandsen KE, Labourel A, HerpoëlGimbert I, Grisel S, Haon M, Lenfant N, Rogniaux H, Ropartz D, Davies GJ, Rosso M-N, Walton PH, Henrissat B, Berrin J-G. Lytic xylan oxidases from wood-decay fungi unlock biomass degradation. Nat Chem Biol. 2018:14(3):306-10.
33. Vu W, Beeson WT, Span EA, Farquhar ER, Marletta MA. A family of starch-active polysaccharide monooxygenases. Proc Natl Acad Sci. 2014;111(38):13822-7.

34. Levasseur A, Drula E, Lombard V, Coutinho PM, Henrissat B. Expansion of the enzymatic repertoire of the CAZy database to integrate auxiliary redox enzymes. Biotechnol Biofuels. 2013;6:41.

35. Chiu E, Hijnen M, Bunker RD, Boudes M, Rajendran C, Aizel K, Oliéric V, Schulze-Briese C, Mitsuhashi W, Young V, Ward VK, Bergoin M, Metcalf $P$, Coulibaly F. Structural basis for the enhancement of virulence by viral spindles and their in vivo crystallization. Proc Natl Acad Sci. 2015;112(13):3973-8.

36. Yadav SK. Archana, Singh R, Singh PK, Vasudev PG: Insecticidal fern protein Tma12 is possibly a lytic polysaccharide monooxygenase. Planta. 2019;249(6):1987-96.

37. Garcia-Santamarina S, Probst C, Festa RA, Ding C, Smith AD, Conklin SE, Brander S, Kinch LN, Grishin NV, Franz KJ, Riggs-Gelasco P, Lo Leggio $L$, Johansen KS, Thiele DJ. A lytic polysaccharide monooxygenase-like protein functions in fungal copper import and meningitis. Nat Chem Biol. 2020;16(3):337-44.

38. Han YW, Srinivasan VR. Isolation and characterization of a celluloseutilizing bacterium. Appl Microbiol. 1968;16(8):1140-5.

39. Whittle DJ, Kilburn DG, Warren RAJ, Miller RC Jr. Molecular cloning of a Cellulomonas fimi cellulase gene in Escherichia coli. Gene. 1982:17(2):139-45.

40. Gilkes NR, Langsford ML, Kilburn DG, Miller RC Jr, Warren RAJ. Mode of action and substrate specificities of cellulases from cloned bacterial genes. J Biol Chem. 1984;259(16):10455-9.

41. O'Neill G, Warren RAJ, Kilburn DG, Miller RC Jr. Secretion of Cellulomonas fimi exoglucanase by Escherichia coli. Gene. 1986;44(2-3):331-6.

42. Rapp P, Wagner F. Production and properties of xylan-degrading enzymes from Cellulomonas uda. Appl Environ Microbiol. 1986;51(4):746-52.

43. Withers SG, Dombroski D, Berven LA, Kilburn DG, Miller RC, Warren RAJ, Gilkes NR. Direct ${ }^{1} H$ N.M.R. determination of the stereochemical course of hydrolyses catalysed by glucanase components of the cellulase complex. Biochem Biophys Res Commun. 1986;139(2):487-94.

44. Langsford ML, Gilkes NR, Singh B, Moser B, Miller RC Jr, Warren RAJ, Kilburn DG. Glycosylation of bacterial cellulases prevents proteolytic cleavage between functional domains. FEBS Lett. 1987;225(1-2):163-7.

45. Gilkes NR, Warren RAJ, Miller RC Jr, Kilburn DG. Precise excision of the cellulose binding domains from two Cellulomonas fimi cellulases by a homologous protease and the effect on catalysis. J Biol Chem. 1988;263(21):10401-7

46. Owolabi JB, Béguin P, Kilburn DG, Miller RC Jr, Warren RAJ. Expression in Escherichia coli of the Cellulomonas fimi structural gene for endoglucanase b. Appl Environ Microbiol. 1988;54(2):518-23.

47. Gilkes NR, Kilburn DG, Miller RC Jr, Warren RAJ. Structural and functional analysis of a bacterial cellulase by proteolysis. J Biol Chem. 1989:264(30):17802-8

48. Moser B, Gilkes NR, Kilburn DG, Warren RAJ, Miller RC Jr. Purification and characterization of endoglucanase $\mathrm{C}$ of Cellulomonas fimi, cloning of the gene, and analysis of in vivo transcripts of the gene. Appl Environ Microbiol. 1989;55(10):2480-7.

49. Gilkes NR, Claeyssens M, Aebersold R, Henrissat B, Meinke A, Morrison HD, Kilburn DG, Warren RAJ, Miller RC Jr. Structural and functional relationships in two families of $\beta-1,4$-glycanases. Eur J Biochem. 1991:202(2):367-77.

50. Gebler J, Gilkes NR, Claeyssens M, Wilson DB, Béguin P, Wakarchuk WW, Kilburn DG, Miller RC Jr, Warren RAJ, Withers SG. Stereoselective hydrolysis catalyzed by related $\beta-1,4$-glucanases and $\beta-1,4$-xylanases. J Biol Chem. 1992;267(18):12559-61.

51. Macleod AM, Gilkes NR, Escote-Carlson L, Warren RAJ, Kilburn DG, Miller RC Jr. Streptomyces lividans glycosylates an exoglucanase (Cex) from Cellulomonas fimi. Gene. 1992;121(1):143-7.

52. Gilkes NR, Kilburn DG, Miller RC Jr, Warren RAJ, Sugiyama J, Chanzy $\mathrm{H}$, Henrissat B. Visualization of the adsorption of a bacterial endo $\beta-$ I,4-glucanase and its isolated cellulose-binding domain to crystalline cellulose. Int J Biol Macromol. 1993;15(6):347-51.

53. Khanna S, Gauri: Regulation, purification, and properties of xylanase from Cellulomonas fimi. Enzyme Microb Technol. 1993;15(11):990-5. 
54. Ong E, Gilkes NR, Miller RC Jr, Warren RAJ, Kilburn DG. The cellulosebinding domain (CBDCex) of an exoglucanase from Cellulomonas fimi: Production in Escherichia coli and characterization of the polypeptide. Biotechnol Bioeng. 1993;42(4):401-9.

55. Shen H, Tomme P, Meinke A, Gilkes NR, Kilburn DG, Warren RAJ, Miller RC. Stereochemical course of hydrolysis catalysed by Cellulomonas fimi CenE, a member of a new family of $\beta$-1,4-glucanases. Biochem Biophys Res Commun. 1994;199(3):1223-8.

56. Shen H, Gilkes NR, Kilburn DG, Miller RC, Warren RAJ. Cellobiohydrolase $\mathrm{B}$, a second exo-cellobiohydrolase from the cellulolytic bacterium $\mathrm{Cel}$ lulomonas fimi. Biochem J. 1995;311(1):67-74.

57. Clarke JH, Davidson K, Gilbert HJ, Fontes CMGA, Hazlewood GP. A modular xylanase from mesophilic Cellulomonas fimi contains the same cellulose-binding and thermostabilizing domains as xylanases from thermophilic bacteria. FEMS Microbiol Lett. 1996;139(1):27-35.

58. Henrissat B, Teeri TT, Warren RAJ. A scheme for designating enzymes that hydrolyse the polysaccharides in the cell walls of plants. FEBS Lett. 1998;425(2):352-4.

59. Notenboom V, Birsan C, Warren RAJ, Withers SG, Rose DR. Exploring the cellulose/xylan specificity of the $\beta$-1,4-glycanase Cex from CelIulomonas fimi through crystallography and mutation. Biochemistry. 1998;37(14):4751-8

60. Stoll D, Stålbrand H, Warren RAJ. Mannan-degrading enzymes from Cellulomonas fimi. Appl Environ Microbiol. 1999;65(6):2598-605.

61. Stoll D, Boraston A, Stålbrand H, McLean BW, Kilburn DG, Warren RAJ. Mannanase Man26A from Cellulomonas fimi has a mannan-binding module. FEMS Microbiol Lett. 2000;183(2):265-9.

62. McLean BW, Boraston AB, Brouwer D, Sanaie N, Fyfe CA, Warren RAJ, Kilburn DG, Haynes CA. Carbohydrate-binding modules recognize fine substructures of cellulose. J Biol Chem. 2002;277(52):50245-54.

63. Hekmat O, Kim Y-W, Williams SJ, He S, Withers SG. Active-site peptide "fingerprinting" of glycosidases in complex mixtures by mass spectrometry. J Biol Chem. 2005;280(42):35126-35

64. Gao J, Wakarchuk W. Characterization of five $\beta$-glycoside hydrolases from Cellulomonas fimi ATCC 484. J Bacteriol. 2014;196(23):4103-10.

65. Saxena H, Hsu B, De Asis M, Zierke M, Sim L, Withers SG, Wakarchuk W. Characterization of a thermostable endoglucanase from Cellulomonas fimi ATCC484. Biochem Cell Biol. 2018;96(1):68-76.

66. Christopherson MR, Suen G, Bramhacharya S, Jewell KA, Aylward FO, Mead D, Brumm PJ. The genome sequences of Cellulomonas fimi and "Cellvibrio gilvus" reveal the cellulolytic strategies of two facultative anaerobes, transfer of "Cellvibrio gilvus" to the genus Cellulomonas, and proposal of Cellulomonas gilvus sp Nov. PLoS ONE. 2013;8(1):e53954.

67. Abt B, Foster B, Lapidus A, Clum A, Sun H, Pukall R, Lucas S, Glavina Del Rio T, Nolan M, Tice H, Cheng J-F, Pitluck S, Liolios K, Ivanova N, Mavromatis K, Ovchinnikova G, Pati A, Goodwin L, Chen A, Palaniappan K, Land M, Hauser L, Chang Y-J, Jeffries CD, Rohde M, Göker M, Woyke T, Bristow J, Eisen JA, Markowitz V, Hugenholtz P, Kyrpides NC, Klenk H-P. Complete genome sequence of Cellulomonas flavigena type strain (134 ${ }^{\top}$. Stand Genomic Sci. 2010;3(1):15-25.

68. Lombard V, Golaconda Ramulu H, Drula E, Coutinho PM, Henrissat B. The carbohydrate-active enzymes database (CAZy) in 2013. Nucleic Acids Res. 2014:42(D1):D490-5.

69. Simpson PJ, Xie H, Bolam DN, Gilbert HJ, Williamson MP. The structural basis for the ligand specificity of family 2 carbohydrate-binding modules. J Biol Chem. 2000;275(52):41137-42.

70. Nakamura T, Mine S, Hagihara Y, Ishikawa K, Ikegami T, Uegaki K. Tertiary structure and carbohydrate recognition by the chitin-binding domain of a hyperthermophilic chitinase from Pyrococcus furiosus. J Mol Biol. 2008;381(3):670-80

71. CAZypedia Consortium. Ten years of CAZypedia: a living encyclopedia of carbohydrate-active enzymes. Glycobiology. 2018;28(1):3-8.

72. Book AJ, Yennamalli RM, Takasuka TE, Currie CR, Phillips GN Jr, Fox BG. Evolution of substrate specificity in bacterial AA10 lytic polysaccharide monooxygenases. Biotechnol Biofuels. 2014. https://doi. org/10.1186/1754-6834-7-109.

73. Kruer-Zerhusen N, Alahuhta M, Lunin WV, Himmel ME, Bomble YJ, Wilson DB. Structure of a Thermobifida fusca lytic polysaccharide monooxygenase and mutagenesis of key residues. Biotechnol Biofuels. 2017. https ://doi.org/10.1186/s13068-017-0925-7.
74. Forsberg Z, Mackenzie AK, Sørlie M, Røhr ÅK, Helland R, Arvai AS, Vaaje-Kolstad G, Eijsink VGH. Structural and functional characterization of a conserved pair of bacterial cellulose-oxidizing lytic polysaccharide monooxygenases. Proc Natl Acad Sci. 2014;111 (23):8446-51.

75. Valenzuela SV, Ferreres G, Margalef G, Pastor FIJ. Fast purification method of functional LPMOs from Streptomyces ambofaciens by affinity adsorption. Carbohyd Res. 2017:448:205-11.

76. Forsberg Z, Bissaro B, Gullesen J, Dalhus B, Vaaje-Kolstad G, EijsinkVGH. Structural determinants of bacterial lytic polysaccharide monooxygenase functionality. J Biol Chem. 2018;293(4):1397-412.

77. Walton PH, Davies GJ. On the catalytic mechanisms of lytic polysaccharide monooxygenases. Curr Opin Chem Biol. 2016;31:195-207.

78. Vaaje-Kolstad G, Forsberg Z, Loose JSM, Bissaro B, Eijsink VGH. Structural diversity of lytic polysaccharide monooxygenases. Curr Opin Struct Biol. 2017:44:67-76.

79. Frandsen KEH, Tovborg M, Jørgensen Cl, Spodsberg N, Rosso M-N Hemsworth GR, Garman EF, Grime GW, Poulsen J-CN, Batth TS, Miyauchi S, Lipzen A, Daum C, Grigoriev IV, Johansen KS, Henrissat B, Berrin JG, Lo Leggio L. Insights into an unusual Auxiliary Activity 9 family member lacking the histidine brace motif of lytic polysaccharide monooxygenases. J Biol Chem. 2019;294(45):17117-30.

80. Frandsen KEH, Lo Leggio L. Lytic polysaccharide monooxygenases: a crystallographer's view on a new class of biomass-degrading enzymes. IUCrJ. 2016;3(6):448-67.

81. Kelley LA, Mezulis S, Yates CM, Wass MN, Sternberg MJE. The Phyre2 web portal for protein modeling, prediction and analysis. Nat Protoc. 2015;10(6):845-58.

82. Vu VV, Beeson WT, Phillips CM, Cate JHD, Marletta MA. Determinants of regioselective hydroxylation in the fungal polysaccharide monooxygenases. J Am Chem Soc. 2014;136(2):562-5.

83. Arora R, Bharval P, Sarswati S, Sen TZ, Yennamalli RM. Structural dynamics of lytic polysaccharide monoxygenases reveals a highly flexible substrate binding region. J Mol Graph Model. 2019;88:1-10.

84. Zhou X, Qi X, Huang H, Zhu H. Sequence and structural analysis of AA9 and AA10 LPMOs: An insight into the basis of substrate specificity and regioselectivity. Int J Mol Sci. 2019;20(18):4594.

85. Frandsen KEH, Simmons TJ, Dupree P, Poulsen J-CN, Hemsworth GR, Ciano L, Johnston EM, Tovborg M, Johansen KS, Von Freiesleben P, Marmuse L, Fort S, Cottaz S, Driguez H, Henrissat B, Lenfant N, Tuna F, Baldansuren A, Davies GJ, Lo Leggio L, Walton PH. The molecular basis of polysaccharide cleavage by lytic polysaccharide monooxygenases. Nat Chem Biol. 2016;12(4):298-303.

86. Simmons TJ, Frandsen KEH, Ciano L, Tryfona T, Lenfant N, Poulsen JC, Wilson LFL, Tandrup T, Tovborg M, Schnorr K, Johansen KS, Henrissat B, Walton PH, Lo Leggio L, Dupree P. Structural and electronic determinants of lytic polysaccharide monooxygenase reactivity on polysaccharide substrates. Nat Commun. 2017;8(1):1064.

87. Bissaro B, Isaksen I, Vaaje-Kolstad G, Eijsink VGH, Røhr ÅK. How a lytic polysaccharide monooxygenase binds crystalline chitin. Biochemistry. 2018;57(12):1893-906.

88. Jensen MS, Klinkenberg G, Bissaro B, Chylenski P, Vaaje-Kolstad G, Kvitvang HF, Nærdal GK, Sletta H, Forsberg Z, Eijsink VGH. Engineering chitinolytic activity into a cellulose-active lytic polysaccharide monooxygenase provides insights into substrate specificity. J Biol Chem. 2019;294(50):19349-64.

89. Vaaje-Kolstad G, Horn SJ, van Aalten DMF, Synstad B, Eijsink VGH. The non-catalytic chitin-binding protein CBP21 from Serratia marcescens is essential for chitin degradation. J Biol Chem. 2005;280(31):28492-7.

90. Freudl R. Signal peptides for recombinant protein secretion in bacterial expression systems. Microb Cell Fact. 2018;17(1):52.

91. Courtade G, Le SB, Sætrom GI, Brautaset T, Aachmann FL. A novel expression system for lytic polysaccharide monooxygenases. Carbohyd Res. 2017;448:212-9.

92. Forsberg Z, Røhr ÅK, Mekasha S, Andersson KK, Eijsink VGH, VaajeKolstad G, Sørlie M. Comparative study of two chitin-active and two cellulose-active AA10-type lytic polysaccharide monooxygenases. Biochemistry. 2014;53(10):1647-56.

93. Russo DA, Zedler JAZ, Wittmann DN, Möllers B, Singh RK, Batth TS, van Oort B, Olsen JV, Bjerrum MJ, Jensen PE. Expression and secretion of a Iytic polysaccharide monooxygenase by a fast-growing cyanobacterium. Biotechnol Biofuels. 2019;12:74. 
94. Eijsink VGH, Petrovic D, Forsberg Z, Mekasha S, Røhr ÅK, Várnai A, Bissaro $B$, Vaaje-Kolstad G. On the functional characterization of lytic polysaccharide monooxygenases (LPMOS). Biotechnol Biofuels. 2019;12:58.

95. Bennati-Granier C, Garajova S, Champion C, Grisel S, Haon M, Zhou S, Fanuel M, Ropartz D, Rogniaux H, Gimbert I, Record E, Berrin J-G. Substrate specificity and regioselectivity of fungal AA9 lytic polysaccharide monooxygenases secreted by Podospora anserina. Biotechnol Biofuels. 2015;8:90.

96. Hall M, Bansal P, Lee JH, Realff MJ, Bommarius AS. Cellulose crystallinity - a key predictor of the enzymatic hydrolysis rate. FEBS J. 2010;277(6):1571-82.

97. Zhang X, Qu T, Mosier NS, Han L, Xiao W. Cellulose modification by recyclable swelling solvents. Biotechnol Biofuels. 2018;11:191.

98. Klemm D, Heublein B, Fink H-P, Bohn A. Cellulose: fascinating biopolymer and sustainable raw material. Angewandte Chemie Int Edn. 2005;44(22):3358-93.

99. Bansal P, Hall M, Realff MJ, Lee JH, Bommarius AS. Multivariate statistical analysis of X-ray data from cellulose: A new method to determine degree of crystallinity and predict hydrolysis rates. Biores Technol. 2010;101(12):4461-71.

100. Elazzouzi-Hafraoui S, Nishiyama Y, Putaux J-L, Heux L, Dubreuil F, Rochas C. The shape and size distribution of crystalline nanoparticles prepared by acid hydrolysis of native cellulose. Biomacromol. 2008;9(1):57-65.

101. Stålbrand H, Mansfield SD, Saddler JN, Kilburn DG, Warren RAJ, Gilkes NR. Analysis of molecular size distributions of cellulose molecules during hydrolysis of cellulose by recombinant Cellulomonas fimi $\beta-1,4-$ glucanases. Appl Environ Microbiol. 1998;64(7):2374-9.

102. Hangasky JA, Marletta MA. A random-sequential kinetic mechanism for polysaccharide monooxygenases. Biochemistry. 2018;57(22):3191-9.

103. Kjaergaard CH, Qayyum MF, Wong SD, Xu F, Hemsworth GR, Walton DJ, Young NA, Davies GJ, Walton PH, Johansen KS, Hodgson KO, Hedman $\mathrm{B}$, Solomon El. Spectroscopic and computational insight into the activation of $\mathrm{O}_{2}$ by the mononuclear $\mathrm{Cu}$ center in polysaccharide monooxygenases. Proc Natl Acad Sci. 2014;111 (24):8797-802.

104. Bissaro B, Røhr ÅK, Müller G, Chylenski P, Skaugen M, Forsberg Z, Horn SJ, Vaaje-Kolstad G, Eijsink VGH. Oxidative cleavage of polysaccharides by monocopper enzymes depends on $\mathrm{H}_{2} \mathrm{O}_{2}$. Nat Chem Biol. 2017;13(10):1123-8.

105. Semisotnov GV, Rodionova NA, Razgulyaev OI, Uversky VN, Gripas AF, Gilmanshin Rl. Study of the "molten globule" intermediate state in protein folding by a hydrophobic fluorescent probe. Biopolymers. 1991;31(1):119-28.

106. Niesen FH, Berglund $\mathrm{H}$, Vedadi M. The use of differential scanning fluorimetry to detect ligand interactions that promote protein stability. Nat Protoc. 2007;2(9):2212-21.

107. Corrêa TLR, Júnior AT, Wolf LD, Buckeridge MS, Dos Santos LV, Murakami MT. An actinobacteria lytic polysaccharide monooxygenase acts on both cellulose and xylan to boost biomass saccharification. Biotechnol Biofuels. 2019;12:117.

108. Beeson WT, Vu VV, Span EA, Phillips CM, Marletta MA. Cellulose degradation by polysaccharide monooxygenases. Annu Rev Biochem. 2015;84:923-46.

109. Zhang R, Liu Y, Zhang Y, Feng D, Hou S, Guo W, Niu K, Jiang Y, Han L, Sindhu L, Fang $X$. Identification of a thermostable fungal lytic polysaccharide monooxygenase and evaluation of its effect on lignocellulosic degradation. Appl Microbiol Biotechnol. 2019;103(14):5739-50.

110. Agrawal D, Basotra N, Balan V, Tsang A, Chadha BS. Discovery and expression of thermostable LPMOs from thermophilic fungi for producing efficient lignocellulolytic enzyme cocktails. Appl Biochem Biotechnol. 2019;191(2):463-81.

111. Vu W, Ngo ST. Copper active site in polysaccharide monooxygenases. Coord Chem Rev. 2018;368:134-57.

112. Gregory RC, Hemsworth GR, Turkenburg JP, Hart SJ, Walton PH, Davies GJ. Activity, stability and 3-D structure of the Cu(II) form of a chitinactive lytic polysaccharide monooxygenase from Bacillus amyloliquefaciens. Dalton Trans. 2016;45(42):16904-12.

113. Hemsworth GR, Taylor EJ, Kim RQ, Gregory RC, Lewis SJ, Turkenburg $J$ P, Parkin A, Davies GJ, Walton PH. The copper active site of CBM33 polysaccharide oxygenases. J Am Chem Soc. 2013;135(16):6069-77.

114. Singh RK, Blossom BM, Russo DA, Van Oort B, Croce R, Jensen PE, Felby C, Bjerrum MJ. Thermal unfolding and refolding of a lytic polysaccharide monooxygenase from Thermoascus aurantiacus. RSC Adv. 2019;9(51):29734-42.

115. Frommhagen M, Koetsier MJ, Westphal AH, Visser J, Hinz SWA, Vincken JP, Van Berkel WJH, Kabel MA, Gruppen H. Lytic polysaccharide monooxygenases from Myceliophthora thermophila C1 differ in substrate preference and reducing agent specificity. Biotechnol Biofuels. 2016;9:186.

116. Navarro D, Rosso M-N, Haon M, Olivé C, Bonnin E, Lesage-Meessen L, Chevret D, Coutinho PM, Henrissat B, Berrin J-G. Fast solubilization of recalcitrant cellulosic biomass by the basidiomycete fungus Laetisaria arvalis involves successive secretion of oxidative and hydrolytic enzymes. Biotechnol Biofuels. 2014;7:143.

117. Jagadeeswaran G, Gainey L, Prade R, Mort AJ. A family of AA9 lytic polysaccharide monooxygenases in Aspergillus nidulans is differentially regulated by multiple substrates and at least one is active on cellulose and xyloglucan. Appl Microbiol Biotechnol. 2016;100(10):4535-47.

118. Reguera G, Leschine SB. Chitin degradation by cellulolytic anaerobes and facultative aerobes from soils and sediments. FEMS Microbiol Lett. 2001;204(2):367-74.

119. Edgar RC. MUSCLE: a multiple sequence alignment method with reduced time and space complexity. BMC Bioinform. 2004;5:113.

120. Kumar S, Stecher G, Tamura K. MEGA7: molecular evolutionary genetics analysis version 7.0 for bigger datasets. Mol Biol Evol. 2015;33(7):1870-4

121. Miller MA, Pfeiffer W, Schwartz T: Creating the CIPRES Science Gateway for inference of large phylogenetic trees. In: Proceedings of the Gateway Computing Environments Workshop (GCE): 2010; New Oreleans, LA. IEEE: pp. 1-8.

122. Jones DT, Taylor WR, Thornton JM. The rapid generation of mutation data matrices from protein sequences. Bioinformatics. 1992;8(3):275-82.

123. Studier FW. Protein production by auto-induction in high-density shaking cultures. Protein Expr Purif. 2005;41(1):207-34.

124. Sundqvist G, Stenvall M, Berglund H, Ottosson J, Brumer H. A general, robust method for the quality control of intact proteins using LC-ESIMS. J Chromatogr B. 2007:852(1-2):188-194.

125. Wu S-C, Lia Y-K. Application of bacterial cellulose pellets in enzyme immobilization. J Mol Catal B Enzym. 2008:54(3-4):103-8.

126. Zhang YHP, Cui J, Lynd LR, Kuang LR. A transition from cellulose swelling to cellulose dissolution by o-phosphoric acid: evidence from enzymatic hydrolysis and supramolecular structure. Biomacromol. 2006;7(2):644-8

127. Bey M, Zhou S, Poidevin L, Henrissat B, Coutinho PM, Berrin J-G, Sigoillot JC. Cello-oligosaccharide oxidation reveals differences between two lytic polysaccharide monooxygenases (family GH61) from Podospora anserina. Appl Environ Microbiol. 2013;79(2):488-96.

128. Bai N, Roder H, Dickson A, Karanicolas J. Isothermal analysis of thermofluor data can readily provide quantitative binding affinities. Sci Rep. 2019;9(1):2650.

129. Creagh AL, Tiong JWC, Tian MM, Haynes CA, Jefferies WA. Calorimetric studies of melanotransferrin (p97) and its interaction with iron. J Biol Chem. 2005;280(16):15735-41.

130. Westereng B, Arntzen M $\varnothing$, Aachmann FL, Várnai A, Eijsink VGH, Agger JW. Simultaneous analysis of $\mathrm{C} 1$ and $\mathrm{C} 4$ oxidized oligosaccharides, the products of lytic polysaccharide monooxygenases acting on cellulose. $J$ Chromatogr A. 2016;1445:46-54.

131. Hegnar OA, Petrovic DM, Bissaro B, Alfredsen G, Várnai A, Eijsink VGH. $\mathrm{pH}$-Dependent relationship between catalytic activity and hydrogen peroxide production shown via characterization of a lytic polysaccharide monooxygenase from Gloeophyllum trabeum. Appl Environ Microbiol. 2018;85(5):e02612-02618.

132. Jagadeeswaran G, Gainey L, Mort AJ. An AA9-LPMO containing a CBM1 domain in Aspergillus nidulans is active on cellulose and cleaves cellooligosaccharides. AMB Express. 2018;8(1):171.

133. Li X, Beeson WT, Phillips CM, Marletta MA, Cate JHD. Structural basis for substrate targeting and catalysis by fungal polysaccharide monooxygenases. Structure. 2012;20(6):1051-61.

\section{Publisher's Note}

Springer Nature remains neutral with regard to jurisdictional claims in published maps and institutional affiliations. 